\title{
The Curse of Moctezuma: American Silver and the Dutch Disease*
}

\author{
Mauricio Drelichman \\ The University of British Columbia \\ Department of Economics \\ 997 - 1873 East Mall \\ Vancouver, British Columbia \\ Canada V6T 1Z1 \\ drelichm@interchange.ubc.ca
}

\footnotetext{
* I am extremely indebted to Joel Mokyr for lengthy discussions, precise guidance and financial support of my several trips to revel in heaps of old paper. I would also like to acknowledge financial support and advice from Joseph Ferrie, as well as valuable suggestions from Ran Abramitzky, Fabio Caldieraro, Jose I. Garcia de Paso, Deirdre McCloskey, Peter Meyer, Lyndon Moore, Sergio Rebelo, Angela Redish, participants at the 2002 Cliometrics Conference, and at seminars at Northwestern University and Universidad de San Andres. I wish to thank James Hamilton for making his software for estimating Markov switching models freely available. Additional financial support from a Northwestern University Graduate Research Grant, from the Robert Eisner Memorial Fund and from an Institute for Humane Studies Hayek Award for Scholars is gratefully acknowledged. Finally, I wish to acknowledge the valuable research assistance provided by Mercedes Delgado Garcia, Fernanda Zapatero and Guillermo Zapatero. The many errors that remain are exclusively my own.
} 


\begin{abstract}
This study formalizes and empirically tests the conjecture that the discovery of large silver reserves in its American colonies during the 1540s triggered in Spain a case of Dutch disease, diverting factors of production to non-traded goods industries and undermining the Spanish comparative advantages in the Early Modern Age. I develop an open-economy model to mimic the economic conditions in Imperial Spain, and test its implications using new price indexes for traded and non-traded goods in a Markov-switching regression framework. I identify a strong and persistent increase in the relative price of non-traded goods coinciding with the silver discoveries, lasting for almost three decades and reversing itself only after the 1575 and 1579 crown bankruptcies.
\end{abstract}

JEL Classification: N1, N5

Keywords: Early Modern Spain, Dutch Disease, Prices, Consumption Baskets, Switching Regression. 


\section{Introduction}

According to a popular legend, the dying Aztec emperor Moctezuma used his last breath to utter a curse under which any strangers who plundered the riches of his land would suffer from painful diseases. As in the case of many legends, there is no historical evidence that the curse was actually uttered, and Spanish accounts of the emperor's death actually report that his last wishes were that Hernan Cortes, whom he still considered a god, took care of the upbringing of his children. Today, many visitors experience firsthand the curse of Moctezuma in Mexican tourist resorts, but Spain, for three centuries the mistress of the lands once ruled by the Aztecs, may have fallen prey to a far more dreadful and lasting economic malaise as a result of the plunder of Mexican and Peruvian treasures.

Spain could, upon entering the last two decades of the sixteenth century, boast an empire on which the sun never set. American silver from Potosi and Zacatecas fueled its war machine and oiled the wheels of power, making it possible for Charles V to humiliate France and seize the crown of the Holy Roman Empire and for Philip II to annex Portugal and its vast dominions, claim the Mediterranean as a Spanish-controlled sea, and dream of invading England with the Invincible Armada. Spain commanded more resources than any other power of its time and perhaps extended its reach over more territory than any other nation in history. The economy flourished under the lead of the regions of Castile and Andalusia. The Castilian plains were home to more than half of the Spanish population, served as the center of royal power, hosted the renowned fairs of Medina del Campo, and dominated the wool trade, Spain's flagship industry. Andalusia held a monopoly of trade with the new world, tallying the shipments of precious metals and engrossing the crown's finances by collecting the royal fifth. Yet, less than a century later, Spain had lost Portugal and its empire as well as the Low Countries, its economy was in 
sharp decline, its technology lagged behind that of the rest of Europe, and its population had dropped considerably. Its naval might had vanished with the Armada's rout in 1588, and France was the new hegemonic power in continental Europe. Even the American empire, its principal mines exhausted or no longer profitable, became a reason for concern as the British, the Portuguese, and the Dutch challenged time and again the Spanish trade monopoly.

Several reasons are often cited as causing or aggravating the Spanish decline of the seventeenth century, most importantly the failure to control fiscal outlays, the simultaneous and ill-fated involvement on several military fronts, and Malthusian dynamics. ${ }^{1}$ Starting with the arbitristas at the end of the sixteenth century, several authors have pointed to the influx of precious metals as a significant source of Spanish economic woes. ${ }^{2}$ Since Earl Hamilton's 1934 study, the bullion flows from the New World into Spain have been scrutinized time and again by the scholarly literature; unfortunately, interest in the topic has often drifted in a purely monetary direction, either ignoring or attaching little significance to the effects of the vast silver imports on long term trade and production patterns, as well as to the overall level of economic performance. ${ }^{3}$ Starting with Corden $(1981,1984)$ and Corden and Neary $(1982)$, a vast literature has examined how the discovery of large quantities of tradable natural resources (or a sudden increase in the price of existing resources) can cause the manufacturing sector to shrink, a phenomenon known

\footnotetext{
${ }^{1}$ See Phillips (1987) for a concise overview of Spanish decline and a discussion of a Malthusian framework.

${ }^{2}$ The arbitristas were moral and political writers who flourished at the beginning of the seventeenth century. Their writings (arbitrios) were proposals to the king advocating economic, political, and social reform. Hamilton's concluding paragraph in his 1938 article (pp. 178-179) is worth quoting in full: "In a grave national emergency economists were right, for once, in their diagnoses and prescriptions. With prophetic vision, the Spanish economists of the seventeenth century (Sancho de Moncada, Pedro Fernandez Navarrete, Geronimo de Cevallos, Jose Pellicer de Ossau, Diego Saavedra Fajardo, Francisco Martinez Mata, Miguel Alvarez Osorio y Redin, and many others) denounced most of the evils leading Spain to ruin -such as primogeniture, mortmain, vagabondage, deforestation, redundance of ecclesiastics, contempt for manual labor and arts, indiscriminate alms, monetary chaos, and oppressive taxation. Their reform programme comprised technological education, immigration of artisans, monetary stability, extension of irrigations, and improvement of internal waterways. History records few instances of either such able diagnosis of fatal social ills by any group of moral philosophers or of such utter disregard by statesmen of sound advice."

${ }^{3}$ See Flynn (1978, 1979), Morineau (1985), and Fisher (1989) for just a few selected examples.
} 
as the Dutch disease after the impact of 1970s natural gas price increases on the Dutch economy. Forsyth and Nicholas (1983) have suggested that these dynamics might have indeed been present in the Spanish case, where the natural resource in question happened to have a straightforward use as international currency. Their article, however, does not present empirical evidence of any kind, nor does it go beyond the Corden and Neary version of the model, which is not sufficient to account for long-term backwardness. Wijnbergen (1984) and Krugman (1987) have argued that, in the presence of an industry learning curve in traditional industrial sectors, the effects of deindustrialization may not be reversible once the natural resources are exhausted or their prices fall below the threshold of profitability. Asea and Lahiri (1999) have further elaborated on the role of resources booms in slowing human capital accumulation; Baland and Francois (2000) have linked them to increased rent seeking activity and the ensuing loss of economic efficiency, while Tornell and Lane (1999) have illustrated the distortions they might introduce in government policies. Although the term Dutch disease originally referred only to a reallocation of resources away from the manufacturing sector, in the wake of the recent literature it has come to evoke the whole set of adverse effects stemming from a resource windfall.

Dutch disease models have typically taken the form of partial equilibrium constructs. In static versions, such as Corden $(1981,1984)$ and Corden and Neary (1982), the economies are resilient in nature, with the effects of the resource boom disappearing as soon as the stimulus is withdrawn. Intertemporal frameworks that yield lasting effects usually obtain them through specific assumptions, such as the learning curve in Krugman (1987). Such permanent effects, however, only hold in partial equilibrium analysis. In section III I propose a general equilibrium model based on Rebelo and Vegh (1995), where lasting adverse effects from a resource boom 
can be obtained if agents incorrectly perceive the temporary nature of the resource windfall as permanent.

The Dutch disease hypothesis has several testable implications. The one that has emerged most robust across different models is a real exchange rate appreciation, defined as a rise in the price of non-traded goods relative to that of traded goods. ${ }^{4}$ The general equilibrium model I develop yields this prediction as well, which can be tested using only price and expenditure data, two of the few (if not the only) economic variables for which reliable time series covering this period can be assembled. I then proceed to construct price indexes for both traded and non-traded goods, relying on Hamilton's price data and my own weighting baskets, obtained from primary sources. I finally use a Markov-switching regression econometric framework to assess whether the evidence supports the Dutch disease conjecture. In the context of the intertemporal equilibrium framework, my results can also be interpreted as a test of the permanent income hypothesis.

Even if the presence of Dutch disease were confirmed at its strongest, its contribution to the decline of Spain remains open to debate. With no national income or trade accounts available, determining the size and impact of a shift in resources away from the manufacturing sector is an arduous task. An obvious concern is the small percentage of national income accounted for by trade in early modern economies. Several authors, however, have pointed out the perils of focusing just on the volume of trade. ${ }^{5}$ In our case, by looking only at the volume of trade at one specific point in time, one risks overlooking the dynamic effects of trade specialization and the

\footnotetext{
${ }^{4}$ See, for example, Edwards (1984), Fardmanesh (1991), and Musonda and Luvanda (1991). For an exception, obtained by imposing learning curves in both the booming and the lagging sectors of the economy, see Torvik (2001).

${ }^{5}$ For two recent examples closely related to early modern Spain see Flynn and Giráldez (2002) and Pomeranz (2000).
} 
associated accumulation of human capital on long run growth. ${ }^{6}$ Although the size of international exchanges in any given year may have been small, much of whatever economic growth European economies experienced in both the short and long run was most likely a result of the processes ignited by trade. If Spain neglected its nascent manufacturing industries while indulging in the availability of large quantities of bullion and missed out on several decades of specialization, its prospects in the European marketplace after the silver stopped flowing must have been bleak at best.

The ramifications of a resource boom can go far beyond altering patterns of trade and specialization. Resource abundance has recently been linked to the presence and perpetuation of rent-seeking behavior and institutions. ${ }^{7}$ Spanish trade was laden with medieval remnants, such as the merchant guilds or consulados, and the Mesta, the powerful association representing transhumant shepherds. The crown, which received at times up to one third of its revenues in the form of American silver, had no need to strike compromises with its constituencies at large, nor did it have any incentive to strike down long established privileges. Its key ally, the Catholic Church, saw a great expansion in its entitlements, inheriting large fortunes, collecting duties, and acting as the main long term lender through the censo, a form of mortgage. After the flow of mineral wealth subsided, or any other negative wealth shocks struck, Spain may have found itself saddled with perverse institutions that slowed modernization and growth. ${ }^{8}$

\footnotetext{
${ }^{6}$ For a historical analysis of the dynamic effects of trade on the Cantabrian regional economy, see Grafe (2001). ${ }^{7}$ See Tornell and Lane (1999), Baland and Francois (2000), Torvik (2002).

${ }^{8}$ For a discussion of the negative effect of rent seeking on the accumulation of human capital and economic growth, see Murphy, Shleifer, and Vishny (1991, 1993). DeLong and Shleifer (1993) document a relationship between autocratic types of government and lower urban population growth (which they use as a proxy for economic growth) in the eight centuries preceding the industrial revolution.
} 


\title{
II. Silver and economic conditions in imperial Spain
}

\author{
Silver, the natural resource
}

The fate of the Spanish empire was closely tied to the flows of American bullion. Figure 1 shows the evolution of imports of American treasure in real terms, constructed using the data from Chart I in Hamilton (1934) and the silver price index reported in its Appendix VIII. ${ }^{9}$ The flow of treasure did not become important until 1550, but after that date a river of silver ran through Spain. Another large increase came after 1580, coinciding with the annexation of Portugal and its dominions, but certainly not caused by it. Treasure imports peaked at the end of the reign of Philip II, coinciding with the zenith of imperial expansion.

[Insert Figure 1 here]

The death of Philip II in 1598 is generally considered the beginning of Spanish decline, and it also marks the beginning of the decline in the flow of bullion. The sharpest decrease came in the period 1635-1640, at a time when the empire suffered its hardest blow with the independence of Portugal in 1640. The Peace of Westphalia in 1648 marked the demise of Spain as an European hegemonic power and reduced the Holy Roman Empire to a mere shell. By that time, American treasure was no longer among Spain's main sources of income.

\footnotetext{
${ }^{9}$ There is some question as to the accuracy of the Hamilton figures for bullion imports, owing to the fact that they draw exclusively on official documents and are therefore susceptible to the effects of underreporting and smuggling. Morineau (1985) has argued that the decline in remittances reported by Hamilton is an artifact of ever increasing contraband. His competing series, constructed on the basis of journalistic and diplomatic reports published in Dutch gazettes, shows a steady flow of bullion throughout the seventeenth century. While the argument is attractive, and Hamilton's figures are bound to suffer from the effects of contraband, Morineau's figures stand in stark contrast to the well documented crisis in New World mining after 1620 [Flynn (1982), Andrien (1985)]. Silver profits were rapidly declining because of epidemics among the Indian labor force, increasing production and administrative costs, and falling silver prices. Viceregal reports starting in 1629 attest to widespread shortages of mercury, a key element in the production process, and by 1660 mining tax receipts in Peru had fallen by more than a third relative to only a decade earlier. It is difficult to reconcile this evidence with the admittedly informal Dutch gazettes reports. While Hamilton's data are clearly a lower bound, Morineau's should be taken as a high upper bound.
} 
Flynn (1982) traces the increase in the flow of silver from the Indies to the invention of the mercury amalgam mining process. American mines were particularly well suited for this procedure, and were also conveniently located in the vicinity of mercury sources. The reduction in remittances to Spain in the seventeenth century is attributed to reduced profitability, stemming from the decline in the purchasing power of silver and ever-increasing costs in the colonies. ${ }^{10}$

Silver constitutes a classic tradable booming sector as defined in the Dutch disease literature. It rose to prominence after a combination of discoveries of natural resources and technological advances, but less than a century later it had lost most of its appeal as a result of the continuous erosion of its profitability. Officially, the Crown was entitled to the "royal fifth" of all private imports of treasure. When supplemented with its own mining, the amount of bullion imports under the direct control of the Crown reached the average of $26 \%$ calculated by Hamilton. In difficult financial times, however, most of the treasure ended up in the hands of the Crown anyway upon being tallied at the Casa de la Contratacion, either through lending, voluntary or forced, or outright confiscation. These enormous resources did not prevent the Crown from getting deeper and deeper into debt and declaring bankruptcy in 1556, 1575, 1579, 1607, 1627, 1647, and $1656 .{ }^{11}$ This dire situation was prompted by the insolvency of all the Spanish dominions, excluding the Indies. Even the Netherlands, whose revenues were usually greater than any other single source, including remittances from the Indies, were a source of financial drain, as the costs of the military campaigns in the Low Countries far exceeded the income they generated. ${ }^{12}$ The Spanish Crown relied on the silver flows as its hard-currency base to incur high levels of indebtedness, which it hoped to pay back with the proceeds of the territories it would

\footnotetext{
${ }^{10}$ Flynn (1982), p. 141; Andrien (1985), p. 61. See also note 10.

${ }^{11}$ The impressive string of bankruptcies conceals their different characteristics; in some of them, such as the 1557 one, only short-term loans contracted with the international banking houses were defaulted upon. In others (1575, for example) long-term bonds held by Spaniards also fell in default.

${ }^{12}$ Flynn (1982), p. 146.
} 
conquer with its military campaigns and with the future remittances of American mines. Neither of these prospects materialized and the Spanish imperial adventure quickly gave way to a much starker picture. $^{13}$

\section{The trading economy of the Early Modern Age}

The bulk of economic activity in Spain took place in Castile, the central heartland where the Crown established its roots during the Moorish wars and where the system of fairs provided the main venue for commercial exchange and credit clearing. Andalusia emerged as a commercial center thanks to the privileged position of its Atlantic ports, at the gateway to the winds that enabled transatlantic voyages. Seville, the main Andalusian city, enjoyed a monopoly of colonial trade and housed the Casa de la Contratacion, responsible for tallying the bullion remittances. Other important centers of activity were the Mediterranean ports of Barcelona and Valencia, as well as the cities on the Cantabrian shore.

The most important Castilian export was high quality wool from transhumant merino herds, its production controlled by the Mesta and its distribution monopolized by the consulado of Burgos; it was followed by salt, cochineal (a reexport from the Indies), oil, iron, leather manufactures, hides, and sugar (also a reexport). ${ }^{14}$ Imports consisted of textile manufactures, including woolen and linen cloth, cotton manufactures, fish, various spices, tin and metal products, guns and gunpowder, flax and hemp, timber and naval stores, books, and paper. ${ }^{15}$ Important exports from other regions included wine and olive oil from Andalusia, salt from Ibiza, and iron, alum, and

\footnotetext{
${ }^{13}$ This particular course of events may even render moot the debate on the magnitude of the decline in bullion flows for the purposes of this study. The negative outcome of the Crown's military adventures meant that whatever quantities could possibly be extracted from the American mines would have had to be employed in meeting debt payments. While the insufficiency of bullion remittances forced the Crown to declare repeated bankruptcies, a higher flow of silver would have accrued directly to the foreign financiers of the Crown rather than to Spanish nationals.

${ }^{14}$ Lynch (1991), p. 193; Braudel (1972), pp. 122, 228, 695; Rich and Wilson (1967), pp. 160, 182, 184, 280,291

${ }^{15}$ Lynch (1991), p. 194; Braudel (1972), pp. 155, 228, 243, 381, 420, 425, 448, 590, 608; Rich and Wilson (1967), pp. 157, 177, 159, 162, 163, 169, 173, 174, 178, 192, 287, 288, 421, 553.
} 
codfish from the Basque country. ${ }^{16}$ Other exports included almonds, oranges, figs, raisins, and soap from Andalusia, nuts, legumes, sardines, and anchovies from the Mediterranean coast, rice, and saffron from Valencia in particular. ${ }^{17}$

Spain exported mainly primary commodities, while importing products with a high added value, at times manufactured from her own raw materials. Shipping services had to be purchased from the Dutch and British, as the Spanish fleets were clearly insufficient and almost exclusively engaged in the trade of the Indies, when not under royal requisition in times of war. ${ }^{18}$ This lack of industrialization prompted Kamen's dismissal of the Spanish decline as a mere construction: "It is difficult to see how so an undeveloped nation could have declined before ever becoming rich. ${ }^{119}$ As Flynn (1982) points out, it is easy to confuse Spain with its empire; the acquisition of foreign territories did not mean that industries were flourishing at home. Yet, if decline means the loss of industrial scope, evidence of a decline there is. The fall in population and the disappearance of numerous crafts and industries forced Spain to start importing many commodities in which she was once self-sufficient, such as corn, rice, and sugar, or even those she used to provide to the world, such as leather manufactures, iron, and alum. ${ }^{20}$ Production of fine wool declined sharply, spelling the demise of Burgos, the once thriving center of the wool trade. ${ }^{21}$ The Basque country lost its competitiveness in iron goods and even the Newfoundland fisheries, successfully exploited by the Basques during most of the sixteenth century, were lost to the French in the 1580 s, never to be recovered. ${ }^{22}$ The population fell dramatically, although the

\footnotetext{
${ }^{16}$ Lynch (1991), p. 193; Braudel (1972), pp. 82, 122, 228, 435, 695; Rich and Wilson, pp. 160-162, 184.

${ }^{17}$ Salvador Esteban (1994), p. 37; Braudel (1972), pp. 42, 82, 119,122, 236, 376, 386, 422, 762, 861; Rich and Wilson (1967), p. 183; Hamilton (1934) p. 233.

${ }^{18}$ Lynch (1991), p. 196; Hamilton (1938), p. 170.

${ }^{19}$ Kamen (1978), p. 41.

${ }^{20}$ Hamilton (1938), p. 170-172; Phillips (1987), pp. 542, 545.

${ }^{21}$ Phillips (1987), pp. 548.

${ }^{22}$ Grafe (2001), p. 61; Phillips (1987), p. 553.
} 
exact magnitude of the decline is unclear. Plagues in 1597-1602 and in 1647-52, the expulsion of the moriscos between 1609 and 1614, emigration, the demand for manpower from the military campaigns of Olivares and reduction in nuptiality and fertility all contributed to large demographic changes. ${ }^{23}$ Livestock numbers were abruptly reduced, perhaps by as much as $60 \%$ between 1600 and 1619, and the size of the fleets trading with America declined significantly between 1575 and $1675 .^{24}$

The traditional traded goods industries in sixteenth and seventeenth century Spain exhibit a behavior that conforms reasonably to the symptoms predicted by Dutch disease theory. It was already recognized at the time that foreign goods were taking over markets that had once been served by Spanish industries. Braudel (1972) quotes the Cortes of Valladolid asking the King in 1586 "to tolerate no longer the importing of candles, glass trinkets, jewelry, cutlery and similar objects from foreign countries which are exchanged, although they are useless luxuries, for gold, as if Spaniards were Indians..." ${ }^{25}$ From providing for the needs of the domestic economy, generating surpluses for international trade, and sustaining vibrant mercantile centers such as Burgos, the Castilian fairs and the Atlantic ports in both Andalusia and the Basque country, Spanish industries gradually fell into stagnation and decline, remarkably when the silver boom was at its peak.

\footnotetext{
${ }^{23}$ Hamilton (1938) placed the fall in population at $25 \%$ and attributed it almost exclusively to the plague. This figure was picked up by Vicens Vives (1969) in his classic work on Spanish economic history and it remained almost undisputed until very recently. Perez Moreda (1994), however, showed that Hamilton's figures were taken from the most hardly hit regions, and that the overall population decline attributable to the plague was, at most, $8 \%$. The expulsion of the Moriscos, on its part, was most relevant in the region of Levant, particularly in Valencia, which expelled some 30,000 families or roughly one third of the population [Phillips (1987), p. 558]. For a discussion of the various factors in population decline, see Elliott (1961), pp. 58-60.

${ }^{24}$ Hamilton (1938), p. 170.

${ }^{25}$ Braudel (1972), p. 519. The unearthing of the detail is attributed by Braudel to Karl Marx in his Zur kritik der politischen oekonomie.
} 


\section{Resource booms in an intertemporal open economy model}

This section presents an intertemporal general equilibrium model styled after Rebelo and Vegh (1995), in which a natural resource windfall can trigger a decrease in welfare if the agents overestimate the increase in wealth. Its testable implication will later be applied to the Spanish case.

\section{Households}

The utility function of the representative household is

$$
U=\sum_{t=0}^{\infty} \beta^{t} \frac{1}{1-1 / \sigma}\left\{\left[\left(C_{t}^{T}\right)^{\gamma}\left(C_{t}^{N T}\right)^{1-\gamma}\right]^{1-1 / \sigma}-1\right\} \quad 0<\gamma<1
$$

where $C_{t}^{T}$ and $C_{t}^{N T}$ denote consumption in period $t$ of tradable and non-tradable goods and $\sigma$ is the intertemporal elasticity of substitution. Households will allocate their labor between the traded and non-traded goods sectors and public employment. Denoting by $N_{t}^{i}$ the amount of labor allocated to sector $i$ in period $t$, and by $N$ the total amount of labor in the economy, we have $N_{t}^{T}+N_{t}^{N T}+N_{t}^{G}=N$

where the superscript $G$ denotes the government sector. Note that no labor is allocated to the extraction of silver. The simplification is warranted because the main source of manpower for the extraction of American mineral was native slave labor. This assumption stands in contrast to classical Dutch disease models and results in more streamlined predictions.

Traded and non-traded goods are produced according to Cobb-Douglas production functions, using fixed sector-specific capital endowments and time invariant productivity factors.

$$
\begin{aligned}
& Y_{t}^{T}=Z^{T}\left(N_{t}^{T}\right)^{\alpha}\left(K^{T}\right)^{1-\alpha} \quad 0<\alpha<1 \\
& Y_{t}^{N T}=Z^{N T}\left(N_{t}^{N T}\right)^{\eta}\left(K^{N T}\right)^{1-\eta} \quad 0<\eta<1
\end{aligned}
$$


$Y_{t}^{i}$ denotes the output of sector $i$ at time $t$, and $Z^{i}$ is the productivity factor for sector $i$. The only public employment is assumed to be in the army, which does not produce any good or service. ${ }^{26}$ The households' budget constraint is $Y_{t}^{T}+p_{t} Y_{t}^{N T}+w_{t} N_{t}^{G}+b_{t-1}(1+r)+s_{t}\left(1-\tau_{t}\right)=C_{t}^{T}+p_{t} C_{t}^{N T}+b_{t}$

where $p_{t}$ is the price of non-traded goods in terms of traded goods (the reciprocal of the real exchange rate) in period $t, w_{t}$ is the wage the government must pay for people to enlist in the army in period $t, b_{t}$ represents the households' net holdings of foreign assets, $r$ is the exogenously given world interest rate, $s_{t}$ denotes the silver inflow in period $t$ and $\tau_{t}$ is the rate at which silver is taxed. Finally, the no-Ponzi game condition for the households is

$$
\lim _{t \rightarrow \infty} \frac{b_{t}}{(1+r)^{t}}=0
$$

\section{The government}

The government collects taxes on private silver flows, funds its military operations, and has access to international financial markets. Its budget constraint is

$$
f_{t-1}(1+r)+s_{t} \tau_{t}=f_{t}+w_{t} N_{t}^{G}+G_{t}
$$

where $f_{t}$ denotes the government net holdings of foreign assets in period $t$ and $G_{t}$ represents government expenditures that do not require labor. $G_{t}$ is assumed to be exogenous and unproductive. The government's no-Ponzi game condition is

$$
\lim _{t \rightarrow \infty} \frac{f_{t}}{(1+r)^{t}}=0
$$

\section{Requirements of military labor are set exogenously, and thus}

\footnotetext{
${ }^{26}$ The army is necessary to fight wars, which could be modeled as a lottery with positive payoff only in the event of victory. However, given the insolvency of the Spanish dominions, it is unclear whether this was ever the case. Alternatively, the army can be thought of merely as a requirement for the economy's continued existence.
} 
$N_{t}^{G}=\bar{N}^{G}$

\section{Equilibrium in the goods markets}

Assuming all goods are perishable, and thus no inventories are carried over, production of nontraded goods must equal consumption, and production of traded goods must equal their consumption plus the trade balance. That is

$$
\begin{aligned}
& Y_{t}^{N T}=C_{t}^{N T} \\
& Y_{t}^{T}=C_{t}^{T}+T B_{t}
\end{aligned}
$$

where $T B_{t}$ represents the trade surplus in period $t$.

Denoting the sum of private and government foreign assets in the economy by $a_{t}$, we can use equations (5), (7) and (10) to derive the aggregate resource constraint of the economy.

$$
C_{t}^{T}+G_{t}=Y_{t}^{T}+s_{t}-\left[a_{t}-a_{t-1}(1+r)\right]
$$

\section{Optimality}

Assuming $\beta=\frac{1}{1+r}$ to avoid trends in consumption, the first order conditions for the household's maximization problem yield

$$
\begin{aligned}
& \frac{1-\gamma}{\gamma} \frac{C_{t}^{T}}{C_{t}^{N T}}=p_{t} \\
& p_{t} \eta Z^{N T}\left(N_{t}^{N T}\right)^{\eta-1}\left(K^{N T}\right)^{1-\eta}=\alpha Z^{T}\left(N_{t}^{T}\right)^{\alpha-1}\left(K^{T}\right)^{1-\alpha}=w_{t}
\end{aligned}
$$

Equation (13) determines the relative consumption levels of traded and non-traded goods given their relative price, and equation (14) states that the value of the marginal productivity of labor must be equal across sectors, and in turn equal to the wage for serving in the army. 


\section{A boom in natural resources}

Starting from an initial situation with no silver flows, imagine that significant silver reserves are discovered in a given period $t$, guaranteeing a positive flow of bullion between periods $t$ and $t+k$, where $k \in\{0,1,2, \ldots, \infty\}$. The present value of the future resource flows evaluated in period $t$ would be given by

$$
S=\sum_{i=t}^{t+k}\left(\frac{1}{1+r}\right)^{i-t} S_{i}
$$

Assuming perfect foresight by all agents, and given that there are no constraints on the use of financial markets and that Ricardian equivalence holds, the effect of the bullion flows on the economy is equivalent to a one-time infusion of silver equivalent to $S$, or to any other one time increase in permanent wealth. Table 1 summarizes the effects on the main variables of the model resulting from such an increase; for future reference, the effects predicted to follow a decline in population are presented as well.

\section{[Insert Table 1 here]}

After an increase in permanent wealth, consumption of both goods will increase to reflect the expanded household budget constraint. Since non-traded goods must be produced locally, labor must switch from the traded goods to the non-traded goods sector. Physical marginal productivity of labor will increase in the traded sector and decrease in the non-traded sector; since the value of the marginal product of labor must be equal in both sectors by equation (14), $w_{t}$ and $p_{t}$ must increase. And by equation (13), consumption of traded goods will expand relatively more than consumption of non-traded goods. The trade balance will fall by the expansion in consumption plus the reduction in production of traded goods, and the trade deficit will be covered with the interest from increased foreign assets. All the effects from the one-time 
increase in natural resources will be permanent and closely match the symptoms of the Dutch disease: an increase in wages and in prices of non-traded goods, as well as a contraction in the traded goods sector. However, as the model stands, a resource windfall results in permanently increased consumption and utility. Wijnbergen (1984) rightly noted that such an outcome can hardly be labeled a "disease."

\section{Misjudging the nature of the windfall}

The perfect foresight assumption, however, is seldom borne out in economic or political decision-making. It is easy to see how, if households overestimate the magnitude of the future resource stream, they would embark on a consumption path too high to be supported by the income from foreign assets; upon realizing the error in the forecasting of future income, consumption of both traded and non-traded goods will have to fall. The magnitude of the fall will be determined by the magnitude of the error in the nature of the windfall, but under the convex utility function assumed in equation 1, the temporal path of consumption would have been suboptimal vis-à-vis the perfect foresight scenario. If the error is large enough, consumption could fall to a level lower than the original one. Particularly damaging scenarios can occur when the flow of natural resources is incorrectly forecast to grow as time passes. In such cases, the initial jump in consumption would be financed by incurring large foreign indebtedness; when the silver flows fail to materialize, the only options will be large cuts in consumption and, eventually, bankruptcy. The Spanish case, where the silver discoveries prompted large increases in consumption and expenditure, only to be followed by a series of bankruptcies and falling income, seems to echo this last scenario. 


\section{Price indexes and real exchange rates}

The model offers several testable predictions to determine whether the behavior of macroeconomic variables is consistent with a Dutch disease episode, but verifying them all is an impossible task when dealing with developments in a pre-statistical era. Price data, however, are reasonably available for sixteenth and seventeenth century Spain, making it possible to construct price indexes for traded and non-traded goods. Once alternative explanations are ruled out, a significant decrease in the price ratio of traded to non-traded goods, tantamount to a real exchange rate appreciation, would be a strong indication of the presence of Dutch disease. ${ }^{27} \mathrm{~A}$ reversal of this trend coinciding with the initial indications of the exhaustion of silver or with the Crown's bankruptcies would be consistent with the conjecture that Spain misjudged the magnitude of the resources available to her.

When constructing price indexes for remote time periods, a researcher faces three broad problems, namely the source of price data, the selection of a weighting basket, and the statistical treatment of the inevitable gaps in the data. In this section I briefly summarize my approach to each of these problems. The many difficult choices I had to make to transform 500-year-old marks on paper into a measure of Spain's competitiveness are discussed in detail in the appendix.

Price data: Hamilton's legacy

The price data for my indexes is taken from Earl J. Hamilton's American Treasure and the Price Revolution in Spain: 1501-1650 [Hamilton (1934)]. In an effort that spanned over six years, Professor Hamilton and his wife Gladys collected hundreds of thousands of observations from

\footnotetext{
${ }^{27}$ The real exchange rate is defined as the nominal exchange rate adjusted for the differential rates of inflation in the home country and abroad. In a world with commodity money, such as silver, the nominal exchange rate is equal to one, and therefore the real exchange rate equals a foreign price index divided by a domestic price index. From the perspective of the home country, and assuming the law of one price holds, the relevant foreign price index is just an index of traded goods; hence the equivalence of the ratio of the prices of traded goods to the prices of non-traded goods with the real exchange rate.
} 
Spanish archives and created price series for 158 different goods across the regions of Andalusia, New Castile, Old Castile-Leon, and Valencia. ${ }^{28}$

Each yearly observation in Hamilton's dataset is the result of no fewer than three and up to twelve price quotations for each year, adjusted for seasonality and cross-checked with alternative sources for possible alterations as a result of fraud or embezzlement. ${ }^{29}$ These quotations were taken from a vast array of sources, mainly account books from hospitals and monasteries, with occasional observations taken from the accounts of royal households or from victualing of ships to fill in gaps.

Coming from such institutions, the data differ from the typical household consumption basket in some significant ways. Most notably, we do not have any indication of rent payments, since hospitals and monasteries owned the premises in which they functioned. ${ }^{30}$ Hamilton's data are also scarce in textiles, the only usable series being the prices of linen in Old Castile-Leon. Metals are also poorly represented in the series. Even wool, Castile's flagship export, registers

\footnotetext{
${ }^{28}$ Hamilton defined regional boundaries by whether their product markets were integrated. Old Castile and Leon, which occupy the northern plains of the peninsula, were considered a single region, while New Castile, separated from the former two kingdoms by the Sierras of Guadarrama, Galdos, and Cata, was treated as a separate unit. Old Castile thrived on the fairs of Medina del Campo, and its wool export market at Burgos concentrated the production of most of Spain. Valladollid and Palencia were also important economic centers. New Castile, with its central position, hosted the administration of the collection of kingdoms that formed Spain. Already during the Reconquista, in 1087, the royal capital was transferred from Burgos to the New Castilian town of Toledo, and Philip II would establish it at its definitive site in Madrid in 1561. Andalusia, south of New Castile and separated from it by the Sierra Morena, organized its economic life along the river Guadalquivir, on which Cadiz, Seville, and Cordoba, enjoyed the benefits of the Mediterranean climate and of the American trade. Finally, the region of Levant (also called Valencia), east of Andalusia and New Castile and separated from them by the Sierra Nevada, featured Valencia as its main city. Omitted from this classification are Galicia, Asturias, the Basque Country, Navarre, Aragon, Catalonia, Murcia, and Extremadura. Nonetheless, the four included regions cover over $60 \%$ of the Spanish territory and as much as three fourths of its population and economic life.

${ }^{29}$ See Hamilton (1934), pp. 139-151 and appendix I, p. 309, for an explanation of the sources and methods used in compiling the data. Although this description can be less than clear in some aspects, Hamilton's original worksheets, collected in The Earl J. Hamilton Collection at the Rare Book, Manuscript, and Special Collections Library at Duke University, allow a glimpse into the mechanics of his work. I surveyed in detail the data sheets and annotations corresponding to American Treasure and the Price Revolution in Spain: 1501-1650, to gain some insight into the construction of his series and obtained many of the sources that I later used to construct our consumption baskets.

${ }^{30}$ The interested reader can find some isolated observations of rent payments from peasant families to monasteries, the largest landowners of the time, in Brumont (1984), pp. 32-35. These observations, however, are quoted in kind, in terms of different goods, and cover only the period from 1550 to 1580 , making it virtually impossible to obtain a reliable series from them.
} 
observations for only the last fifty years of the period, and even then there is no indication of its quality.

Despite its shortcomings, Hamilton's dataset remains the standard source for Spanish price history of this period. Occasional amendments for particular goods have surfaced, but there is no other data source so comprehensive, both in time and in scope.

The problem of weights: some new data

While a rich literature has addressed the Price Revolution in Spain, the choice of a basket of weights has been perhaps its most persistent shortcoming. Hamilton did not use weights at all, and his indexes are arithmetic means of all the available prices. ${ }^{31}$ Brown and Hopkins (1959) provided consumption weights for Valencia, based on a combination of their weight basket for sixteenth-century England with some anecdotal evidence. Martin Aceña (1992) adopted the Brown and Hopkins basket to calculate his price index for Castile. More recently, Llopis et al. (2000) have corrected some biases in the Brown-Hopkins basket and have enlarged it to include 31 goods. All these works, however, use very rough estimates of the consumption basket, based mainly on qualitative appreciations. I attempt to correct this shortfall in the literature by constructing what I believe are the first consumption baskets for sixteenth and seventeenth century Spain based on quantitative data extracted from primary sources.

Table 2 reports the consumption baskets obtained from the household of Queen Joanna in Tordesillas (Old Castile) in 1546, ${ }^{32}$ those presented in Llopis (2000) for rich and poor households, ${ }^{33}$ and the weights from the Hospital de las Cinco Llagas in Seville in $1623 .{ }^{34}$ Since

\footnotetext{
${ }^{31}$ Hamilton (1934), p. 149.

${ }^{32}$ Archivo de Simancas, Casas y Sitios Reales 12 (29), Simancas (Valladolid).

${ }^{33}$ The Llopis baskets, which subsume all the previous research in the area, are reproduced here for comparison purposes. It should be noted that both of them add to slightly more than $100 \%$.

${ }^{34}$ Archivo de la Diputacion Provincial, Hospitales 114, Sevilla (Sevilla).
} 
these baskets contain dozens of different goods, I grouped them into relevant categories in order to compare them with previous research. For the two baskets that I computed, I also report the percentage of each category composed of traded goods. ${ }^{35}$ I used less complete or reliable sources to check the consistency of the computed weights. These include books that report only expenditures on certain categories, such as the kitchen accounts of the Hospital de Esgueva for 1659 (Old Castile) $;^{36}$ books that report only a summary of expenses aggregated in broad categories, such as the Convento de San Pablo in Toledo (New Castile) $;^{37}$ and sources that seemed suspicious because of extremely abnormal weights in some of the leading goods, such as the books of Hospital de las Cinco Llagas in $1587^{38}$ or the Household of Prince Philip. ${ }^{39}$ The nature of my sources naturally raises questions of representative sampling and structural change over time. The interested reader is referred to the appendix for a thorough discussion of these issues.

[Insert Table 2 here]

My two sets of weights represent two very different institutions, one of which was ministering to the poor in the center of colonial trade in the seventeenth century, while the other was providing for a confined queen in the middle of the Castilian plain eighty years earlier. The series from the household of Queen Joanna is comparable to the Llopis basket for rich households, since they come from roughly the same period, region, and social stratum. When relevant categories are considered together (such as meat and live animals, or cereal and bread) the weights are roughly in the same range, except for wine (which Llopis estimates at a high $15 \%$ of consumption) and textiles (which are somewhat low in my estimates, but perhaps too high in Llopis's). My basket,

\footnotetext{
${ }^{35}$ See the appendix for a detailed discussion of how goods were classified as traded or non-traded.

${ }^{36}$ Archivo Historico Municipal, Hospital 120 (313), Valladolid (Valladolid).

${ }^{37}$ Archivo Historico Nacional, Clero Secular Regular Libros 16026, Madrid.

${ }^{38}$ Archivo de la Diputacion Provincial, Hospitales 109, Sevilla (Sevilla).

${ }^{39}$ Archivo de Simancas, Casas y Sitios Reales 74, Simancas (Valladolid).
} 
however, exhibits a much wider array of goods, enabling me to include more price series in the indexes. ${ }^{40}$ While many of these commodities represent small expenditures, some of them gain relevance when estimating separate indexes for traded and non-traded goods.

\section{The nuts and bolts of constructing the price indexes}

Before obtaining usable price indexes, there are a few remaining obstacles to address. In the first place, it is necessary to compile baskets of weights that match the available price series for each region; the baskets I compiled contain a large number of goods, while a much smaller number of price series are sufficiently complete to be usable. Then we need to assess the impact of missing data on the reliability of the series, choose a suitable base period, and estimate corrections to the biases built into the weights. In the appendix I describe in detail the use of category-based reweighting, non-parametric bounds, and sensitivity analysis to ensure that the indexes reasonably reflect the behavior of prices and the real exchange rate.

Armed with price indexes for traded and non-traded goods for each of the four Spanish regions surveyed by Hamilton (1934), I set out to construct real exchange rate series. The results are expressed as an index of the relative price of traded goods in terms of non-traded goods; a fall in the index indicates a real exchange rate appreciation, the movement predicted by the Dutch disease model. As discussed in the appendix, the price indexes take the form of a lower and an upper bound; a large gap between the bounds indicates that missing data make it impossible to pin down a sufficiently narrow region where the true index may reside. The real exchange rate will also be expressed as a set of bounds. The lower bound is constructed dividing the lower bound on the appropriate traded goods index by the upper bound on the corresponding non-

\footnotetext{
${ }^{40}$ It must be kept in mind that, while Table 2 reports expenditure categories, our actual consumption baskets consist of individual goods. The basket computed from Queen Joanna's accounts is based on 3583 separate entries for 215 different goods, although many of them appear only once and carry very small weights. Llopis's baskets, in contrast, contain 31 goods for the rich households and 24 for the poor ones.
} 
traded goods index. Conversely, the upper bound is constructed dividing the upper bound on the traded goods index by the lower bound on the non-traded goods index.

Figure 2 shows a 4-year moving average of my estimates of the upper and lower bounds for the real exchange rate in each of the four regions. The thin lines in each picture represent the upper and lower bounds for the real exchange rate, while the solid black line is their mean value. The first striking feature is the high volatility, with the maximum observed values for the real exchange rate being twice as high as the minimum ones in some cases. Some of the troughs coincide exactly with large demographic changes, such as the recurring plagues in the opening years of the seventeenth century; since a fall in population would have the effect of decreasing available labor, thereby increasing the price of non-traded goods, this observation is a very welcome consistency test for the model. Other extreme values are more difficult to explain; while the volatility is undoubtedly linked to the high weight of food staples in the indexes, some of them, such as wheat, fall into the traded category, while others, such as fresh meats, are nontraded. Bad harvests, a breakdown in trade, a cattle epidemic, and many other factors could result in substantial movements in the series. Finally, while the sixteenth century was largely free of inflation driven by fiat money, seventeenth century monarchs normally resorted to minting copper money, changing the units of account, and debasing the currency, in ever more desperate attempts to cover fiscal deficits and service their overwhelming debt. ${ }^{41}$ These large monetary disturbances may have had diverse effects on different categories of goods, causing large swings in the real exchange rate.

\section{[Insert Figure 2 here]}

\footnotetext{
${ }^{41}$ See MacKay (1981). For a comprehensive account of monetary units and changes in their gold content in the sixteenth and seventeenth century, Hamilton (1934) provides a good starting point; however, the corrections by Motomura (1994, 1997) must be kept in mind.
} 
A simple inspection of the bounds reveals that the Andalusian data are too weak to be useful; there are almost no price observations before 1550 , and in the second half of the sixteenth century missing data are so pervasive that the bounds are too wide to draw useful conclusions. Not without regret, we need to abandon the study of this region, which held a crucial position in the colonial trading system, until more consistent price series are compiled.

\section{Estimating the timing and size of regime changes}

The model presented in section III predicts discrete jumps in the price of non-traded goods relative to traded goods, tantamount to the real exchange rate, whenever new information regarding the present value of silver flows is unveiled. If a Dutch disease episode did indeed take place, one would expect to see a substantial real exchange rate appreciation when the knowledge of newly found wealth is incorporated by decision makers; conversely, a negative wealth shock, such as the realization that silver was not that plentiful or valuable after all, that a bankrupt government was likely to confiscate any new bullion shipment, or that military defeats would mean higher taxation, would be associated with a real exchange rate depreciation. One would therefore like to test if the real exchange rate in Spain was subject to regime changes, and, if so, to date them and estimate their magnitude. Regime changes associated with the discovery of silver mines and real exchange rate appreciations would strongly support the Dutch disease hypothesis; similarly, regime changes coinciding with adverse wealth shocks and real exchange rate depreciations would help to determine the point at which the effects of the riches from the New World were offset by other problems in the minds of decision makers.

Most econometric specifications used to estimate the magnitude of regime changes require that the timing of the change be exogenously specified. The timing of a real exchange rate appreciation, however, is a crucial piece of evidence in linking it to the silver flow; imposing the 
timing exogenously would strip the estimation of most of its identifying power. It is highly preferable to let the data reveal whether there was a regime change and, if so, when it took place. I therefore adopt an econometric specification based on J. D. Hamilton's (1995) model of structural change, which makes it possible to estimate the timing as well as the magnitude of any change in mean and variance the real exchange rate series may exhibit. Once the regime changes are identified and dated, I will establish whether they coincide with relevant economic events, such as the silver discoveries. Finally, I will determine if the average real exchange rate moved in the direction predicted by the model, and whether it did so by a substantial magnitude. If these three conditions are met, the Dutch disease hypothesis will have withstood its first empirical test. I define a regime as the agents' perception of their permanent wealth. This is an unobserved variable, the value of which one would like to infer from observation of the real exchange rate. For simplicity, I will treat the regime as a discrete-valued variable, $s_{t}$, measuring agents' perception of their permanent wealth. The relationship between the regime and the real exchange rate stems from the theoretical framework.

Consider the following $h^{\text {th }}$ order autoregressive specification ${ }^{42}$

$$
y_{t}-\mu\left(s_{t}\right)=\phi_{1}\left[y_{t-1}-\mu\left(s_{t-1}\right)\right]+\phi_{2}\left[y_{t-2}-\mu\left(s_{t-2}\right)\right]+\ldots+\phi_{h}\left[y_{t-h}-\mu\left(s_{t-h}\right)\right]+\sigma\left(s_{t}\right) \varepsilon_{t}
$$

The error terms are assumed to be independent of each other and follow a standard normal distribution. The mean and standard deviation of the autoregressive process in each period $t$ depend on the value of $s_{t}$, which we would like to infer based on observation of the relative price index $y_{t}$. The roots of the polynomial $1-z \phi_{1}-z^{2} \phi_{2}-\ldots-z^{h} \phi_{h}$ are assumed to lie outside the unit circle, thus requiring the series under analysis to be covariance stationary once the changes in regime are accounted for. Let $s_{t}$ takes values in the set $\{1,2, \ldots, S\}$ according to a first order

\footnotetext{
${ }^{42}$ This section closely follows Hamilton (1995), Ch. 22.
} 
Markov process with the associated matrix of transition probabilities $P$, where each element $p_{i j}$ is defined as the probability that $s_{t}=j$ given that $s_{t-1}=i$, and the sum of each column is equal to 1.

$$
P=\left[\begin{array}{cccc}
p_{11} & p_{12} & \cdots & p_{1 S} \\
p_{21} & p_{22} & \cdots & p_{2 S} \\
\vdots & \vdots & \ddots & \vdots \\
p_{S 1} & p_{S 2} & \cdots & p_{S S}
\end{array}\right]
$$

Define $\psi_{t}=\left(y_{t}, y_{t-1}, \ldots, y_{t-m}\right)$ as a vector containing every observation of the real exchange rate through date $t$. If $s_{t}=j$, the conditional density of $y_{t}$ is given by $\eta_{t, j}=f\left(y_{t} \mid s_{t}=j, \psi_{t} ; \alpha\right)$, where $\alpha=\left(\mu_{1}, \ldots, \mu_{S}, \sigma_{1}, \ldots, \sigma_{S}, \phi_{1}, \ldots, \phi_{h}\right)$ is the vector of parameters characterizing the conditional density. We face the problem of estimating $\alpha$ and making inferences on the value of $s_{t}$ in each period.

Let $\Theta$ be a vector collecting the population parameters $\alpha$ and the transition probabilities $p_{i j}$, and assume for the moment that $\Theta$ is known. Let $P\left\{s_{t}=j \mid \psi_{t} ; \Theta\right\}$ be the conditional probability that $s_{t}=j$ based on data obtained through period $t$ and the knowledge of $\Theta$, and collect the probabilities that $s_{t}$ equals each possible state $j$ in the $S \times 1$ vector $\hat{\xi}_{t \mid t}$, which thus represents the inference about the regime in period $t$ using all the information available up to that period. Given observations through date $t$, it is possible to make a forecast about the probability of observing each regime at date $t+1$. Collect these forecasts in $\hat{\xi}_{t+1 \mid t}$, a $S \times 1$ vector where the $j^{\text {th }}$ element equals $P\left\{s_{t}=j \mid \psi_{t} ; \Theta\right\}$.

The non-linear filter derived by Hamilton (1989) obtains the optimal inferences and forecasts about $s_{t}$ by iterating on the following two equations 


$$
\begin{aligned}
& \hat{\xi}_{t \mid t}=\frac{\left(\hat{\xi}_{t \mid t-1} \otimes \eta_{t}\right)}{\mathbf{1}^{\prime}\left(\hat{\xi}_{t \mid t-1} \otimes \eta_{t}\right)} \\
& \hat{\xi}_{t+1 \mid t}=P \hat{\xi}_{t \mid t}
\end{aligned}
$$

where $\otimes$ denotes element-by-element multiplication. The algorithm can be started by setting $\hat{\xi}_{1 \mid 0}$ equal to any vector of nonnegative constants adding up to unity, or to the vector of unconditional probabilities for each state. The first equation yields the probability that $s_{t}$ equals each state $j$ at each time $t$; these are called the filter probabilities. Hamilton (1995) goes on to show that the algorithm also yields the value of the log-likelihood function evaluated at $\Theta$ in the form of

$$
\ell(\Theta)=\sum_{t=1}^{T} \log f\left(y_{t} \mid \psi_{t-1} ; \Theta\right)=\sum_{t=1}^{T} \log \mathbf{1}^{\prime}\left(\hat{\xi}_{t \mid t-1} \otimes \eta_{t}\right)
$$

Using numerical methods on equations (20), (18), and (19) it is possible to obtain the maximum likelihood estimates of $\Theta$ and their associated filter probabilities.

A further improvement on the inference about $s_{t}$ obtained through the filter probabilities can be achieved by calculating the so-called smoothed probabilities, which incorporate all the available data rather than only the observations up to period $t$. The smoothed probabilities can be calculated using the algorithm in Kim (1993):

$$
\hat{\xi}_{t \mid T}=\hat{\xi}_{t \mid t} \otimes\left\{P^{\prime}\left[\hat{\xi}_{t+1 \mid T}(\div) \hat{\xi}_{t+1 \mid t}\right]\right\}
$$

where $(\div)$ denotes element-by-element division. The algorithm is started by using from the Hamilton filter and the smoothed probabilities are obtained by iterating backwards for $t=T-1, T-2, \ldots, 1$.

The above specification requires that both the number of states and the number of autoregressive lags be determined prior to estimation. Given the number of states, the number of lags can be 
determined by using a number of information criteria and verifying the absence of serial correlation in the residuals. Selecting the appropriate number of states is a more complex issue, since some of the parameters in the alternative hypothesis will not be identified under the null, and therefore the Wald, likelihood ratio and Lagrange multiplier tests will not have a standard asymptotic distribution. Garcia and Perron (1996) illustrate the implementation of a number of tests that have been suggested for use in these cases, but their size and power remain mostly unknown. Given the particular restrictions I will later impose on the transition probabilities, the J-test for non-nested hypothesis proposed by Davidson and McKinnon (1981) will be the best suited for model selection in this context.

One potential problem with the above specification is that, in the presence of a highly volatile series and under particular configurations of the data, strong negative autoregressive behavior can be mistaken for a constant alternation between states. My real exchange rate series exhibit high volatility, thus making it difficult to distinguish between changes in the perception of permanent wealth (regime changes) and simple autoregressive behavior. Since it is very unlikely that the perceptions of permanent wealth were constantly subject to dramatic changes, I will impose an identification restriction to explain the volatility through autoregressive effects rather than by frequent regime switching. One way to achieve it would be to apply a low-frequency filter to the data; this approach, however, has the disadvantage of precluding the estimation of short-term properties of the series, such as the volatility of the real exchange rate in each state. An alternative for models with three states or more is to impose a "cycling" restriction, which keeps the data in its original form but requires that after a transition from one state to another, the model has to pass through at least a third state before returning to the original one. ${ }^{43}$ This swings

\footnotetext{
${ }^{43}$ For example, in a case with three states this can be achieved by setting $p_{12}=p_{23}=p_{31}=0$.
} 
the estimates to persistent states, while still allowing for the characterization of the short-term behavior of the series.

\section{The evolution of the real exchange rate}

I conducted several test runs of the Markov switching model on the full 150 observations for the three Spanish regions with sufficiently good data, experimenting with different combinations in the number of states and lags. ${ }^{44}$ Specifications with low numbers of states tended to lump together most of the observations in a single state, reserving the remaining ones only for the highest peaks or lower troughs. Specifications with higher number of states tended to exhibit high volatility, predicting regime changes at almost every period. These results are likely indications of misspecification, which hardly comes as a surprise; the Spanish economy underwent large fundamental transformations and was subject to major exogenous shocks throughout the period, many of which affected the real exchange rate. In particular, the plagues, fiscal crises, demographic changes, and monetary disturbances that became commonplace after 1600 meant that Spain was, in the seventeenth century, a fundamentally different nation from the one that was ruled by Charles V and Philip II. ${ }^{45}$ Another likely source of trouble is the low quality of the data in the first quarter of the sixteenth century, a period for which only a few sources survive, and those that do are far less systematic and reliable than comparable ones later on. In order to alleviate the misspecification problems, I concentrate on the years 1531-1600; since the largest silver mines were discovered in the mid-1540s and the fiscal crisis does not become severe until the 1580s (which will also see the first large-scale military disasters), this

\footnotetext{
${ }^{44}$ All the estimations of the Markov switching model were conducted using professor James D. Hamilton's software, available from http://econ.ucsd.edu/ jhamilto/software.htm.

${ }^{45}$ Another problem is our use of a single weighting basket for the whole 150 year period, which is likely to introduce significant biases in the price indexes given these large structural changes.
} 
time frame allows between one and two decades on each side of the period where I expect to identify a Dutch disease phenomenon.

When estimating the switching regression model on the 1531-1600 subsample, the information criteria and the J-tests select models with three states and no autoregressive lags for New Castile, while three states and two autoregressive lags were selected for Old Castile. ${ }^{46}$ In the case of Valencia, the tests point to a one-lag specification under two states and two-lag specification under three states. However, the smoothed probabilities in the two-state models mimic the shortterm fluctuations in the series, assigning one state to each single trough observation and the other state to everything else. This makes me lean towards the three-state specification, which is restricted to identify persistent states and results in much more plausible estimates. I report the estimates for the three selected models in Table 3.

[Insert Table 3 here]

Figures 3 to 5 show the results for each of the three regions. In the top panel of each figure I reproduce the real exchange rate series without any filtering or smoothing. In the bottom panel, I report the smoothed probabilities for the process being in each of the three states at each point in time. The solid line represents the probability of the series being in the state with the lowest mean ("low state") and the dotted line represents the probability of it being in the state with the second lowest mean ("medium state"). The probability of being in the state with the highest mean ("high state") is just one minus the other two probabilities. Thus, when the solid line approaches a value of 1 , it reveals that the economy is in a low exchange rate state, and is therefore likely to be experiencing a Dutch disease episode.

\footnotetext{
${ }^{46}$ I used the Akaike Information Criterion and the Bayesian Information Criterion, which yielded concurring results.
} 
In the results for New Castile, shown in Figure 3, the high state was needed only to accommodate the peak of 1549 , while all the other years correspond to the medium and low states. The low state is in effect between 1550 and 1580; from the estimates in Table 3, the real exchange rate during that period is on average $11 \%$ lower than in the medium state years. The volatility of the real exchange rate in the low state is less than one half of that in the medium state. These results are strongly consistent with the presence of Dutch disease between 1550 and 1580; while the real exchange rate on occasion sinks to low values outside this period, the appreciation is nowhere so persistent as during these three decades.

[Insert Figure 3 here]

The results for Old Castile follow a similar pattern. A high mean, high volatility state is present in the years 1539-1546, while the rest of the period is split between the low and medium state in a fashion similar to that of New Castile. The appreciation episode starts in 1547 and gradually disappears during the 1570s and 1580s. However, the difference between the low and the medium states is only $4.8 \%$. While significant at the $1 \%$ confidence level, this magnitude comes across as somewhat small given the noisy nature of the data.

\section{[Insert Figure 4 here]}

Valencia, the final region, exhibits a different behavior. There are no outlying observations, and therefore no need to use a state to account for them. The real exchange rate, however, hovers around different values before and after the appreciation episode. The series starts in a medium state, falls into a low state around 1554, and switches to a high state in 1577 . In the low state, the real exchange rate is on average $14.2 \%$ lower than in the medium state, and $25 \%$ lower than in the high state. The volatility does not change from state to state. These results are again consistent with a period of Dutch disease between 1554 and 1577. This episode of real exchange 
rate appreciation, while a few years shorter on each end, is consistent with the ones estimated for New and Old Castile.

\section{[Insert Figure 5 here]}

In all three regions, the econometric framework detects a persistent real exchange rate appreciation starting between 1547 and 1554, and concluding in the late 1570s. The beginning of the appreciation episodes coincides remarkably with the discovery of American silver reserves and the development of the industrial processes needed to exploit them; their conclusion, some three decades later, coincides with the 1575 bankruptcy. This timing, endogenously estimated through the econometric framework, supports the conjecture that the silver discoveries were treated as a large increase in permanent income; the real depreciation at the end of the $1570 \mathrm{~s}$ points to the bankruptcy both as a negative wealth shock in itself and as an ominous signal of worse ones to come.

The persistence of the real exchange rate appreciation in all three regions makes it easy to rule out alternative explanations. While many economic and demographic events might result in an increase in the price of non-traded goods, few would be capable of sustaining it for almost three decades, and much less go unnoticed. The strongest contenders for such an effect are large demographic changes and persistent monetary disturbances. While Spain suffered from both of them in the seventeenth century, its population was fairly stable between 1530 and 1600, and the Habsburgs maintained a rigid policy of sound money even in the face of the Crown's financial hardships.

The heterogeneity of the price data across the different regions prevented me from constructing standardized indexes, as the choice of goods included in each case was necessarily dictated by the availability of the relevant series. The baskets I used, while based on the same fundamental 
weights, vary substantially across regions, reflecting the surviving price series in each case. These differences are particularly noticeable in the case of non-traded goods. This shortfall, however, doubles as a sui generis robustness test, lending further support to my results, as the increase in the relative price of non-traded goods is consistent across regions despite the variations in the baskets.

\section{Conclusions}

Soon after completing its reunification under Ferdinand and Isabella, Spain embarked on a thoroughly expansionist program, as reflected in the ever increasing size of the Spanish government under Charles V and Philip II, and its pervasiveness through all aspects of economic life. ${ }^{47}$ The already indebted crown resorted to creative finance, leveraging the expected revenues from the Indies to assemble powerful armies and fleets with which to project its power over the known world and be the first to reach the yet unknown. Fueled by American treasure, this drive dwarfed any other factors that might explain the movements of the real exchange rate in the second half of the sixteenth century, which confirm that both Crown and private individuals expected increasing revenues, either from American mines or from military conquest. Large demographic changes or monetary disturbances, the main contenders when it comes to persistent changes in the real exchange rate, came too late to have any possible impact.

Spain's rosy expectations were not to be. Military defeats and dwindling profitability in the colonies soon put the government's budget on an unsustainable deficit spiral; when the Crown was first forced to default on domestically held debt in 1575 , it became clear that the resources available to Spain had been miscalculated or would not suffice to sustain its expansion in any case. The perception of permanent income by individuals dropped sharply, causing a

\footnotetext{
${ }^{47}$ Ulloa (1977), the classic account on the finances of Philip II, is an excellent source on the impact of taxes and public debt on the economy of the kingdom.
} 
corresponding depreciation in the real exchange rate. The synchronization between imports of bullion, bankruptcies, and the persistent increase in the relative price of non-traded goods strongly support the Dutch disease hypothesis in a permanent income framework.

Although the real exchange rate series appear to reflect strong changes in perceptions of the present value of treasure flows, and of permanent wealth in general, two fundamental questions remain unanswered. What was the magnitude of the effect of the Dutch disease on Spanish trade? And how did it impact the Spanish economy as a whole?

The price indexes can only reveal the presence of Dutch disease; one would need detailed trade statistics to quantify its impact on trade both during and after the silver boom. We do have two crucial pieces of evidence, however. The first one is the actual size of the real exchange rate movements. The $11 \%$ appreciation in New Castile and $14.2 \%$ appreciation in Valencia, while not enormous, are both substantial magnitudes and, crucially, they are persistent enough to rule out the possibility of a statistical artifact. The second piece of evidence, the reversal in the direction of the flow of traded goods, buttresses the case for a loss of competitiveness in those industries which were once the pride of Spanish trade. In the early seventeenth century, for example, as part of a pervasive decline in many traded goods sectors, Spain lost its iron exports to Scandinavia and its textile exports to England; both these regions later leveraged their newly found comparative advantages to sustain their drive towards economic development.

Assessing the overall impact of the Dutch disease on the Spanish economy is a subtler task. One could argue that trade represented a sufficiently small part of Spain's national income and that its effects on the economy as a whole can safely be ignored. While this may be true from a static perspective, it ignores the dynamic effects of specialization on economic growth. In the early modern age, what little growth economies experienced was probably coming from their 
expanding trade. Traded goods industries (and trade itself) fostered the specialization and division of labor that could lead to productivity increases and human capital accumulation, as the rise to prominence of the Low Countries exemplifies. The onset of a phenomenon that severely reduced a country's comparative advantages for an extended period could not have been beneficial for its long-term economic development.

It is worth remembering that the Dutch disease is not the only mechanism through which American silver might have become a curse for Spain. Natural resource windfalls have been shown to encourage rent seeking, and to discourage the accumulation of human capital. Both these phenomena can persist long after the natural resources are exhausted, becoming a lasting negative legacy spurred by a short-term blessing. While here I have focused exclusively on the trade and exchange rate effects of the natural resource windfall, there is surely a much richer picture to be painted on the subject of fiscal and institutional consequences of the silver discoveries.

Scholars and conventional wisdom alike have long set the death of Philip II in 1598 as the beginning of Spain's long decline. Contemporary writers, however, were well aware that something in the inner workings of the empire had been wrong since much earlier. Writing in 1600, Gonzalez de Cellorigo looked at what he saw as the main reason for the already apparent downturn in the fate of the kingdom: "Our Spain has set her eyes so strongly on the business of the Indies, from where she obtains gold and silver, that she has forsaken the care of her own kingdoms; and if she could indeed command all the gold and silver that her nationals keep discovering in the new world, this would not render her as rich and powerful as she would have otherwise been." 48

\footnotetext{
${ }^{48}$ Gonzalez de Cellorigo (1991), p. 50. The translation is my own.
} 


\section{Appendix: Constructing price indexes and real exchange rate series}

The real exchange rate series used in this study are the result of a careful blend of primary and secondary source data, anecdotal evidence, and a detailed review of the existing literature. This appendix details the process of constructing the series, from the sources to the final results.

\section{The data}

The price data are taken from Hamilton's series, which cover 158 different goods across four regions (although not all goods are present in all regions). The first task was to classify the 158 goods according to their trade status. The theoretical literature distinguishes between tradable and non-tradable goods, using the susceptibility of a good to being traded as the classification criterion. I preferred to distinguish between traded and non-traded goods, classifying them according to whether the goods were actually being imported or exported, rather than having the potential to. This choice of criterion was prompted by the difficulty of establishing the susceptibility of a good to being traded; in fact, at a sufficient expense, almost any good can be traded. What matters for real exchange rate movements, however, is whether a given good is actually being traded, or at least whether the domestic markets for the good are contestable by foreign products and vice-versa. I therefore set out to scour the extensive literature on modern age trade in Europe for evidence of the trade status of the goods for which I had price data (see Section II for specific examples and references). Although not every single good could be categorized, those left out have no bearing on the indexes.

Since previous quantitative work on the issue of weighting baskets relied only marginally on primary sources, I decided to grab the bull by the horns. From Hamilton's worksheets, housed at the Rare Book, Manuscript, and Special Collections Library at Duke University, I identified the account books from hospitals, monasteries, and royal households that could contain detailed 
expenditure data. I reviewed a large number of books from institutions in Old Castile, New Castile, and Andalusia, housed in several Spanish archives, and selected those that survived in more complete form. While Hamilton, who published only prices, could afford to use fragmentary information for a given year and control for seasonal variations using the remaining data from other years, a consumption basket that left out any significant length of time within a year could be subject to strong seasonal biases. I therefore computed baskets from those sources for which I had at least one uninterrupted year, and possibly two consecutive years to check for consistency. After selecting a source, all transactions in a given year were entered in a database with fields for the date, the name of the good purchased, the quantity, and the total amount paid. I then classified goods as traded or non-traded and separated them into the broad expenditure categories reported in the row headings of Table 2 . While the quantity purchased was not always contained in the records, only the total expenditure on each good, and not the unit price, is necessary to compute the relative weights. This meant that sources that were not useful to Hamilton for constructing price series because unit prices were not reported could prove useful to me if the records were otherwise complete.

\section{Constructing the weights}

The institutions whose records have survived to the present day hardly resemble the Spanish representative household of the time. Royal households represent the extreme upper tail of the income distribution, while hospitals and monasteries will exhibit consumption patterns that reflect their specific institutional goals. The best approach to identify the nature of the biases for each kind of institution would be to compare the baskets generated by as many different sources as possible in the same general period and note the differences in the leading goods. While I do not have enough data to conduct an analysis of this kind, I can nonetheless spot abnormal 
weights in each basket and identify their potential effect on our results by performing sensitivity analysis. For example, the basket computed from the account books of the Hospital de las Cinco Llagas in Seville in 1587 shows that $8.55 \%$ of the budget was spent on bread and cereals, a suspiciously low figure given that results from all other sources, including other years from the same hospital, range between $25 \%$ and 35\%. Similarly, records from the household of Prince Philip in 1541 showed no purchases of wheat or oil, and minimal purchases of bread and wine, suggesting that these goods were obtained through own production or some other non-market devices.

Since the availability of price series varies significantly across regions, I faced the task of converting the baskets yielded by the primary sources into a set of weights that can be applied to the available price data. To lessen the effects of the asymmetric representation of different categories of goods in our indexes, I used a category-based reweighting procedure. After gathering all the suitable series for a region (which I define as series that registered observations for at least $50 \%$ of the years in the period), I calculated the percentage of each of the categories in Table 2 represented by them. I then assigned to each good a weight equal to its raw weight in the primary sources divided by the percentage of its category covered by the available price data, thus increasing the final weight of goods in categories with poor representation. This reweighting procedure rests on the assumption that the prices of goods in the same category tend to fluctuate together. The categories I used in reweighting differ slightly from the ones presented in Table 2, because in some cases products in different categories could represent the same underlying good, as bread and wheat do. In fact, some institutions bought the cereal and baked their own bread, while others purchased the final product. To keep a certain consistency across institutions, I 
merged the two relevant categories to perform the reweighting. This is why bread is classified in Table 2 as a traded good.

The next obstacle is determining the impact of missing price observations, which were quite pervasive in some periods and regions. While my goal was to exploit the available primary sources to their fullest extent, I found myself time and again in situations where simply no data was available for a particular time frame, or when the numbers yielded by the sources were too incomplete to be used even as auxiliary material. In other instances, the results from a particular account book were in extreme disagreement with the body of established knowledge and with the rest of my own work, leading me to question the reliability of a given source, even if it meant that no data for a particular period would be left.

When faced with the problem of missing data, the econometrician is forced to state what assumptions she is willing to make in order to reach a result. The purist may make no assumptions at all, even if it means that no point estimates will be obtained, and that one must be satisfied with the knowledge that the sought estimates lie within a region that will get wider as the missing data problem gets more pervasive. Others can, at their own risk, make some assumptions regarding the behavior of the data that will lead to narrower bounds or even point estimates. The emergence of non-parametric methods has made it possible to estimate models imposing much less stringent assumptions on the nature of the missing data than previously required; our Markov-switching model, however, requires an uninterrupted time series in order to be properly estimated. I am not aware of a similar non-parametric framework that would allow me to date the changes in regime endogenously as well as estimate their magnitude.

While several econometric techniques are available to impute the missing observations, I think that it is important first to assess the magnitude of the missing data problem and its potential 
implications. Manski (1995) shows how to obtain lower and upper bounds for the true value of a variable by replacing the missing observations alternatively with their minimum and maximum logically possible values, thus imposing no assumptions at all on the behavior of the unobserved data. Since I am dealing with prices, the minimum and maximum logically possible values are zero and infinity respectively; using them would yield meaningless estimates and, indeed, an upper bound equal to infinity. I therefore replaced them with some reasonable extreme values. I calculated the lower bound by filling any gap with either the last observation before it or the first immediately after it, whichever was lower. Similarly, I calculated the upper bound by using the other value. This procedure assumes that any missing price would have been between the two closest observable prices; although this assumption is bound to be wrong in some instances, the persistent price inflation and the resulting upward trend in prices mean that in most cases I will not be far off the mark. Since the bounds are quite tight in the vast majority of years, a moderate relaxation of this assumption is not likely to have a major effect.

Another issue arose with the choice of the base period. To reduce biases, Hamilton (1934) split the series into three 50-year sub-periods, and calculated index numbers for each of them using averages of the middle decades as base periods to minimize the possibility of picking an abnormal year. The successive literature has consistently followed the practice of using the average of prices over a number of years as a base period, although it has tended to rejoin the three sub-periods into one 150 -year long series. This procedure has the potential of incurring considerable index-number biases; however, since I am interested in ratios of index numbers and not in the indexes themselves, my final results would be exempt from any such bias. In fact, both the numerator and the denominator of the ratios would be subject to the same distortion, thus 
canceling each other out. I therefore adopted the decade 1601-1610 as a base, given its relatively central position in the series and the few missing data instances occurring in it.

A final consideration is the weights for traded products. Since the sources will yield consumption baskets, the appropriate magnitudes for traded goods need to be augmented by exports to reflect accurately the composition of the basket relevant to the real exchange rate calculations. Given the total lack of itemized trade statistics, I can only experiment with different plausible magnitudes for the main exports, namely wool, wine, and oil, and note the resulting variations in the indexes, which are never large enough to alter the main results. 


\section{References}

Andrien, Kenneth J. Crisis and decline: the Viceroyalty of Peru in the seventeenth century. Albuquerque: University of New Mexico Press, 1985.

Asea, Patrick K., and Amartya Lahiri. "The Precious Bane." Journal of Economic Dynamics and Control 23 (1999): 823-849.

Baland, Jean-Marie, and Patrick Francois. "Rent-Seeking and Resource Booms." Journal of Development Economics 61 (2000): 527-542.

Braudel, Fernand. The Mediterranean and the Mediterranean world in the age of Philip II. New York: Harper and Row, 1972.

Brown, H. P., and Sheila V. Hopkins. "Builders' wage rates, prices and population; some further evidence." Economica 26 (1959).

Brumont, Francis. Campo y campesinos de Castilla la Vieja en tiempos de Felipe II. Madrid: Siglo XXI de España Editores, 1984.

Corden, W. Max. "The exchange rate monetary policy and North Sea oil: the economic theory of the squeeze of tradables." Oxford Economic Papers 33 (1981), Supplement: 23-46.

Corden, W. Max. "Booming sector and Dutch Disease economics: survey and consolidation." Oxford Economic Papers 36 (1984): 359-380.

Corden, W. Max, and J. Peter Neary. "Booming sector and de-industrialization in a small open economy." The Economic Journal 92 (1982): 825-848.

Davidson, Russell, and James G. MacKinnon. "Several tests for model specification in the presence of alternative hypothesis." Econometrica 49 (1981): 781-793.

DeLong, Bradford J., and Andrei Shleifer. "Princes and merchants: European city growth before the industrial revolution." Journal of Law and Economics 36 (1993): 671-702.

Edwards, Sebastian. "Coffee, money and inflation in Colombia." World Development 12, Nos. 11/12 (1984): 1107-1117.

Elliott, John H. “The decline of Spain.” Past and Present 20 (1961): 52-75.

Fardmanesh, Mohsen. "Dutch Disease economics and the oil syndrome: an empirical study." World Development 19 (1981): 711-717.

Fisher, Douglas. "The price revolution: a monetary interpretation." Journal of Economic History 49 (1989): 883-902.

Flynn, Dennis. O. "A new perspective on the Spanish price revolution: the monetary approach to the balance of payments." Explorations in Economic History 15 (1978): 388-406.

Flynn, Dennis. O., "Spanish American silver and world markets in the sixteenth century." Economic Forum 10 (1979): 46-72.

Flynn, Dennis. O. "Fiscal crisis and the decline of Spain (Castile)." Journal of Economic History 42 (1982): 139-147. 
Flynn, Dennis O. and Arturo Giráldez. "Cycles of silver: global economic unity through the mideighteen century." Journal of World History 13 (2002): 391-427.

Forsyth, Peter. J., and Stephen J. Nicholas. "The decline of Spanish industry and the price revolution: a neoclassical analysis.” Journal of European Economic History 12 (1983): 601-610.

Garcia, Rene, and Pierre Perron. "An analysis of the real interest rate under regime shifts." The Review of Economics and Statistics 78 (1996): 111-125.

Gonzalez de Cellorigo, M. Memorial de la politica necesaria y util restauracion a la Republica de España y estados de ella y del desempeño universal de estos reinos (1600). Madrid: Antoni Bosch, 1991.

Grafe, Regina. Northern Spain between the Iberian and Atlantic worlds: trade and regional specialization, 1550-1650. Unpublished Doctoral Dissertation. London: London School of Economics and Political Science, 1991.

Hamilton, Earl J. “American Treasure and Andalusian Prices, 1503-1660." Journal of Economic and Business History 1 (1928): 1-35.

Hamilton, Earl J. American treasure and the price revolution in Spain, 1501-1650. Cambridge: Harvard University Press, 1934

Hamilton, Earl. J. “The decline of Spain.” Economic History Review 8 (1938): 168-179.

Hamilton, James D. "A new approach to the economic analysis of nonstationary time series and the business cycle." Econometrica 57 (1989): 357-384.

Hamilton, James D. Time Series Analysis. Princeton: Princeton University Press, 1995.

Kamen, Henry. “The decline of Spain: a historical myth?” Past and Present 81 (1978): 35-50.

Kim, Chang-Jin. "Dynamic linear models with Markov switching." Journal of Econometrics 60 (1993): 1-22.

Krugman, Paul. "The narrow moving band, the Dutch Disease and the competitive consequences of Mrs. Thatcher.” Journal of Development Economics 27 (1987): 41-55.

Llopis, Enrique, Miguel Jerez, Adoracion Alvaro, and Eva Fernandez. "Indices de precios de la zona noroccidental de Castilla y Leon, 1518-1650." Revista de Historia Economica 18 (2000): 665-684.

Lopez-Davalillo Larrea, Julio. Atlas Historico de España y Portugal. Madrid: Editorial Sintesis.

Lynch, John. Spain 1516-1598: from nation state to world empire. Cambridge: Basil Blackwell, 1991.

MacKay, Angus. Money, prices and politics in fifteenth century Castile. Royal Historical Society Studies in History Series No. 28, London: Royal Historical Society, 1981.

Martin Aceña, Pablo. "Los precios en Europa durante los siglos XVI y XVII: estudio comparativo." Revista de Historia Economica 10 (1992): 359-395.

Manski, Charles F. Identification Problems in the Social Sciences. Cambridge: Harvard University Press, 1995. 
Morineau, Michel. Incroyables gazettes et fabuleux metaux. London: Cambridge University Press, 1985

Motomura, Akira. "The best and worst of currencies: seigniorage and currency policy in Spain, 1597-1650.” Journal of Economic History 54 (1994): 104-127.

Motomura, Akira. "New data on minting, seigniorage, and the money supply in Spain (Castile), 1597-1643." Explorations in Economic History 34 (1997): 331-367.

Murphy, Kevin, Andrei Shleifer, and Robert Vishny. "The allocation of talent: implications for growth." Quarterly Journal of Economics 106 (1991): 503-530.

Murphy, Kevin, Andrei Shleifer, and Robert Vishny. "Why is rent seeking so costly for growth?" American Economic Review Papers and Proceedings 83 (1993): 409-414.

Musonda, Flora M. and Eliab Luvanda. "The consequences of the 1976-77 coffee boom on the Tanzanian economy: a test of the Dutch Disease model." East Africa Economic Review 7 (1991): $1-17$.

Perez Moreda, Vicente. "The plague in Castile at the end of the sixteenth century and its consequences." In Yun Casalilla, Bartolome, and Thompson, I. A. A. The Castilian crisis of the seventeenth century. London: Cambridge University Press, 1994.

Phillips, Carla Rahn. "Time and duration: a model for the economy of early modern Spain." The American Historical Review 92 (1987): 531-562.

Pomeranz, Kenneth. The great divergence: China, Europe and the making of the modern world economy. Princeton: Princeton University Press, 2000.

Rebelo, Sergio, and Carlos A. Vegh. "Real Effects of Exchange Rate-Based Stabilization: an Analysis of Competing Theories." NBER Working Paper Series, No. 5197 (1995).

Rich, E. E. and Wilson, C. H. (eds.). The Cambridge Economic History of Europe, volume IV. London: Cambridge University Press, 1967.

Salvador Esteban, Emilia. "España y el comercio mediterraneo en la Edad Moderna.” In Lobo Cabrera, Manuel, and Vicente Suarez Grimon (eds.). El comercio en el antiguo regimen. Universidad de Las Palmas de Gran Canaria, 1994.

Tornell, Aaron, and Philip R. Lane. "The voracity effect." American Economic Review 89 (1999): 22-46.

Torvik, Ragnar. "Learning by doing and the Dutch Disease." European Economic Review 45 (2001): 285-306.

Torvik, Ragnar. "Natural resources, rent seeking and welfare." Journal of Development Economics 67 (2002): 455-470.

Ulloa, Modesto. Hacienda Real de Castilla en el reinado de Felipe II. Madrid: Fundacion Universitaria Española, 1977.

Vicens Vives, Jaime. An economic history of Spain. Princeton: Princeton University Press, 1969.

Wijnbergen, Sweder van. "The Dutch Disease: a disease after all?" The Economic Journal 94 (1984): 41-55. 


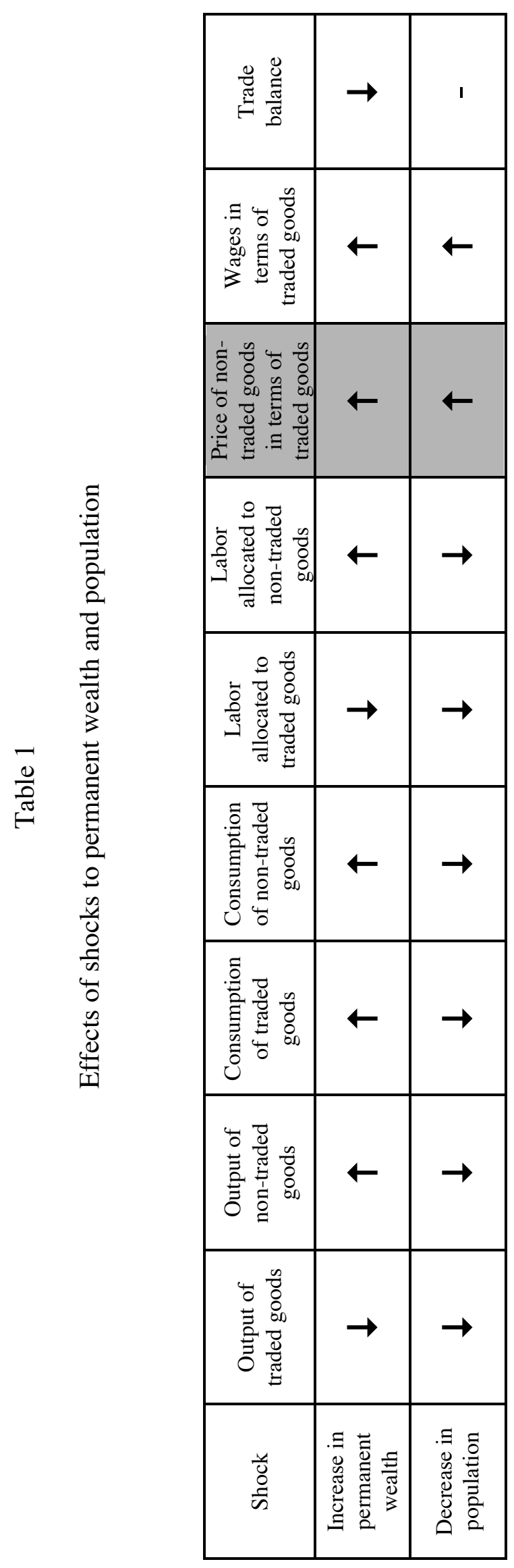




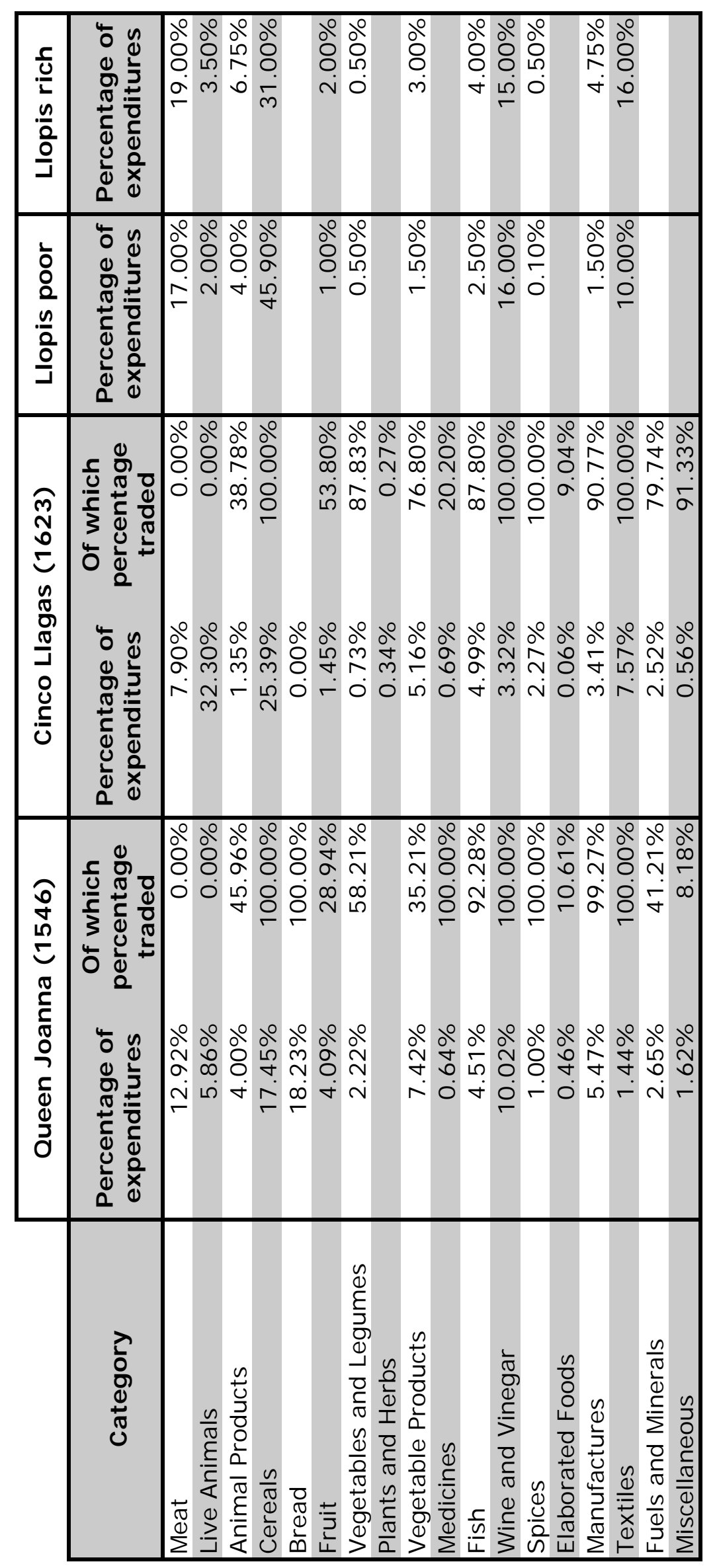


Equation for Old Castile and Valencia:

$$
y_{t}-\mu\left(s_{t}\right)=\phi_{1}\left[y_{t-1}-\mu\left(s_{t-1}\right)\right]+\phi_{2}\left[y_{t-2}-\mu\left(s_{t-2}\right)\right]+\sigma\left(s_{t}\right) \varepsilon_{t} \quad s \in\{1,2,3\}
$$

Equation for New Castile:

$$
y_{t}-\mu\left(s_{t}\right)=\sigma\left(s_{t}\right) \varepsilon_{t} \quad s \in\{1,2,3\}
$$

\begin{tabular}{|c|c|c|c|}
\hline Region & $\begin{array}{c}\text { New } \\
\text { Castile }\end{array}$ & Old Castile & Valencia \\
\hline States & 3 & 3 & 3 \\
\hline Lags & 0 & 2 & 2 \\
\hline $\begin{array}{r}\mu_{1} \\
\text { (High state mean) }\end{array}$ & $\begin{array}{c}1.400 \\
(0.251) \\
\end{array}$ & $\begin{array}{c}1.276 \\
(0.096) \\
\end{array}$ & $\begin{array}{c}1.075 \\
(0.024) \\
\end{array}$ \\
\hline $\begin{array}{r}\mu_{2} \\
\text { (Medium state mean) }\end{array}$ & $\begin{array}{c}1.068 \\
(0.025) \\
\end{array}$ & $\begin{array}{c}1.024 \\
(0.034) \\
\end{array}$ & $\begin{array}{c}0.939 \\
(0.026) \\
\end{array}$ \\
\hline $\begin{array}{r}\mu_{3} \\
\text { (Low state mean) }\end{array}$ & $\begin{array}{c}0.950 \\
(0.019) \\
\end{array}$ & $\begin{array}{c}0.974 \\
(0.014) \\
\end{array}$ & $\begin{array}{c}0.806 \\
(0.029) \\
\end{array}$ \\
\hline $\begin{array}{r}\sigma_{1} \\
\text { (High state volatility) }\end{array}$ & $\begin{array}{c}0.063 \\
(0.064)\end{array}$ & $\begin{array}{c}0.037 \\
(0.019)\end{array}$ & $\begin{array}{c}0.009 \\
(0.003)\end{array}$ \\
\hline $\begin{array}{r}\sigma_{2} \\
\text { (Medium state volatility) }\end{array}$ & $\begin{array}{c}0.020 \\
(0.005)\end{array}$ & $\begin{array}{c}0.005 \\
(0.001)\end{array}$ & $\begin{array}{c}0.008 \\
(0.009)\end{array}$ \\
\hline $\begin{array}{r}\sigma_{3} \\
\text { (Low state volatility) }\end{array}$ & $\begin{array}{c}0.008 \\
(0.002)\end{array}$ & $\begin{array}{c}0.004 \\
(0.001)\end{array}$ & $\begin{array}{c}0.009 \\
(0.003)\end{array}$ \\
\hline$\phi_{1}$ & & $\begin{array}{c}0.513 \\
(0.132)\end{array}$ & $\begin{array}{c}0.389 \\
(0.127)\end{array}$ \\
\hline$\phi_{2}$ & & $\begin{array}{l}-0.259 \\
(0.108)\end{array}$ & $\begin{array}{l}-0.180 \\
(0.128)\end{array}$ \\
\hline $\begin{array}{r}p_{11} \\
\text { (High state persistence) }\end{array}$ & $\begin{array}{c}0.444 \\
(0.512) \\
\end{array}$ & $\begin{array}{c}0.865 \\
(0.116) \\
\end{array}$ & $\begin{array}{c}0.977 \\
(0.035) \\
\end{array}$ \\
\hline $\begin{array}{r}p_{22} \\
\text { (Medium state persistence) }\end{array}$ & $\begin{array}{r}0.970 \\
(0.033) \\
\end{array}$ & $\begin{array}{c}0.967 \\
(0.043) \\
\end{array}$ & $\begin{array}{c}0.979 \\
(0.026) \\
\end{array}$ \\
\hline (Low state persistence) & $\begin{array}{c}0.953 \\
(0.038)\end{array}$ & $\begin{array}{c}0.963 \\
(0.030)\end{array}$ & $\begin{array}{c}0.980 \\
(0.020)\end{array}$ \\
\hline $\log \mathrm{L}$ & 106.681 & 135.606 & 123.728 \\
\hline $\mathrm{N}$ & 70 & 70 & 70 \\
\hline $\mathrm{K}$ & 9 & 11 & 11 \\
\hline B statistic & $\begin{array}{c}0.85 \\
(0.468)\end{array}$ & $\begin{array}{c}0.97 \\
(0.300)\end{array}$ & $\begin{array}{c}0.37 \\
(0.999)\end{array}$ \\
\hline $\mathrm{J} 2$ & 0.017 & 0.173 & \\
\hline $\mathrm{J} 3$ & 0.069 & 0.950 & \\
\hline
\end{tabular}

Models were estimated with the restriction $p_{12}=p_{23}=p_{31}=0$.

Figures in parentheses for the parameter estimates are standard errors.

Figures in parentheses for Bartlett's statistic are p-values. Bartlett's statistic is used to test the null hypothesis that a series is white noise. I use it on the model's residuals to verify that no serial correlation remained.

$\mathrm{J} 2$ is the p-value for the J-test for a two-state null hypothesis versus a 3-state alternative hypothesis. $\mathrm{J} 3$ is the p-value for the converse test. Values are not reported for the Valencian model because the estimation for the 2-states model yielded non-persistent states. 


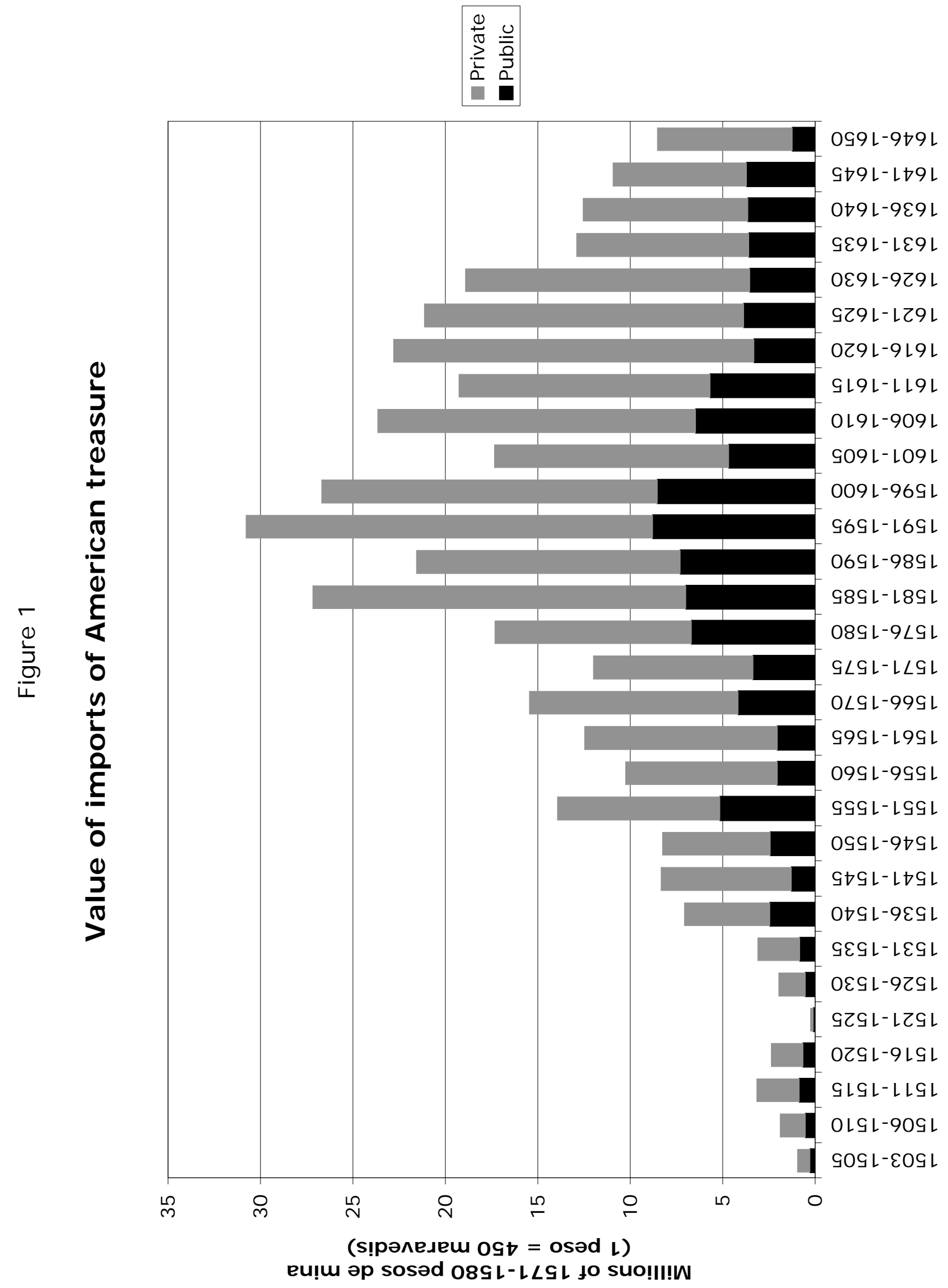



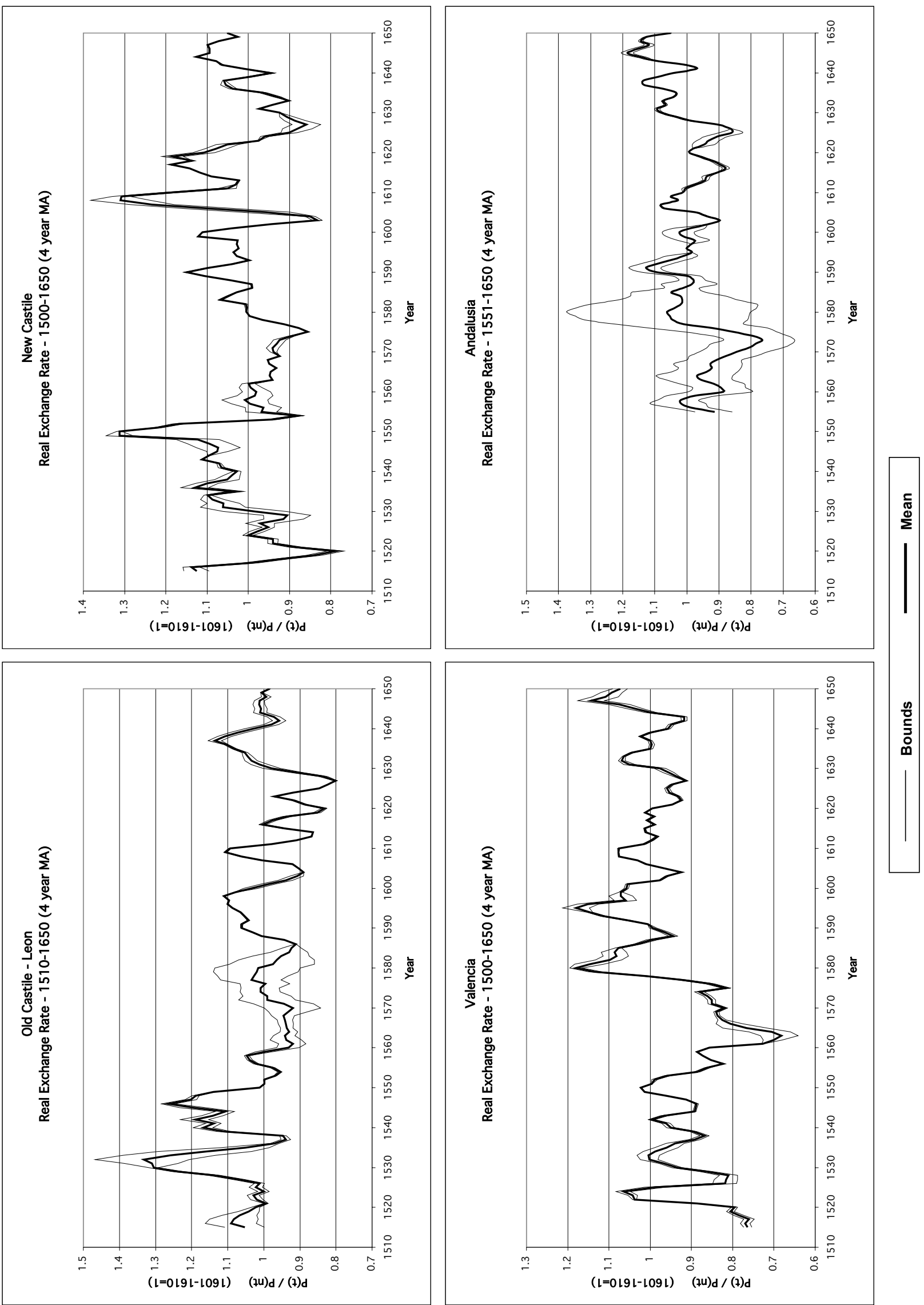

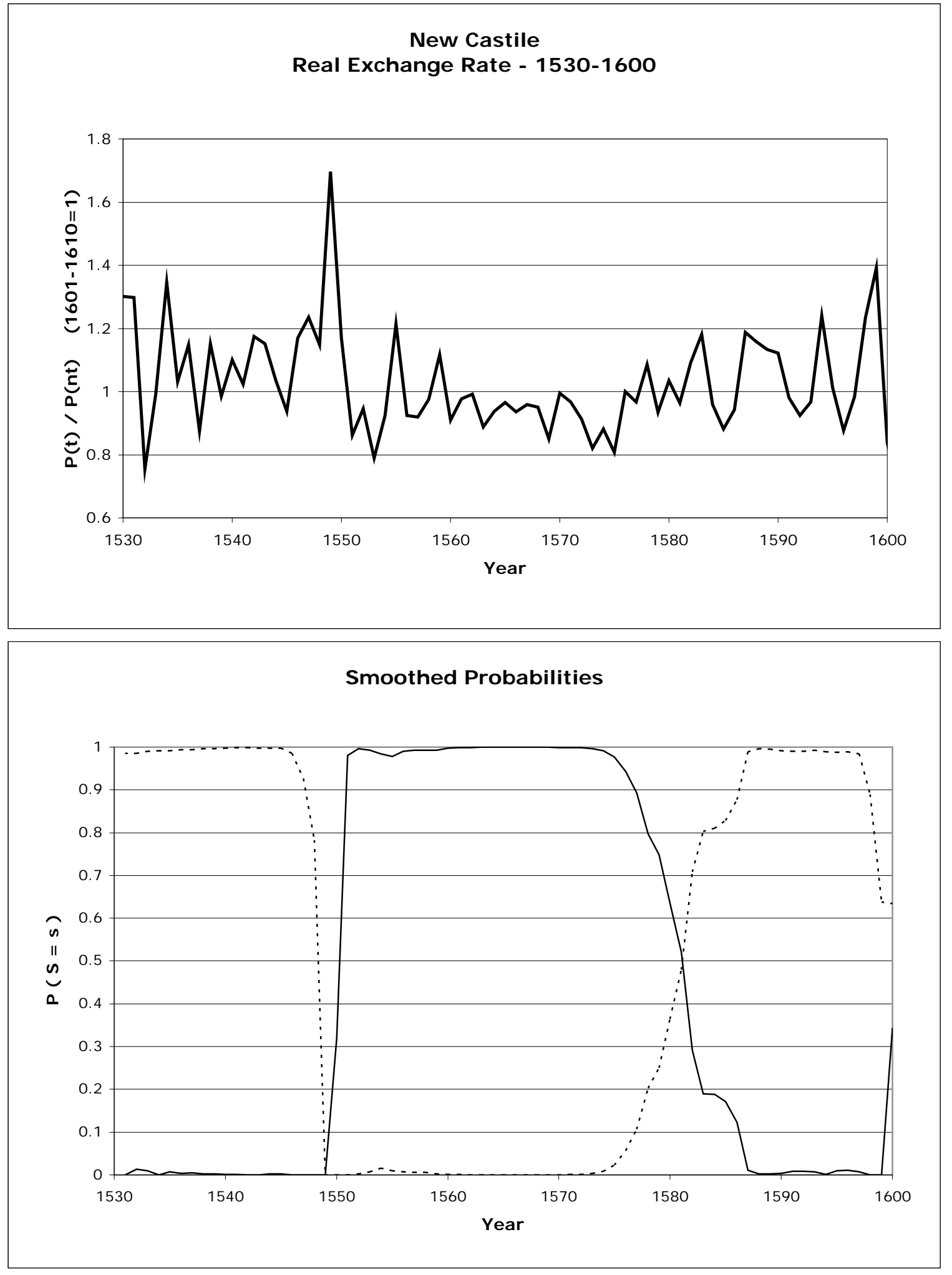

Probability of the series being in a "low" state (Dutch disease)

Probability of the series being in a "medium" state 

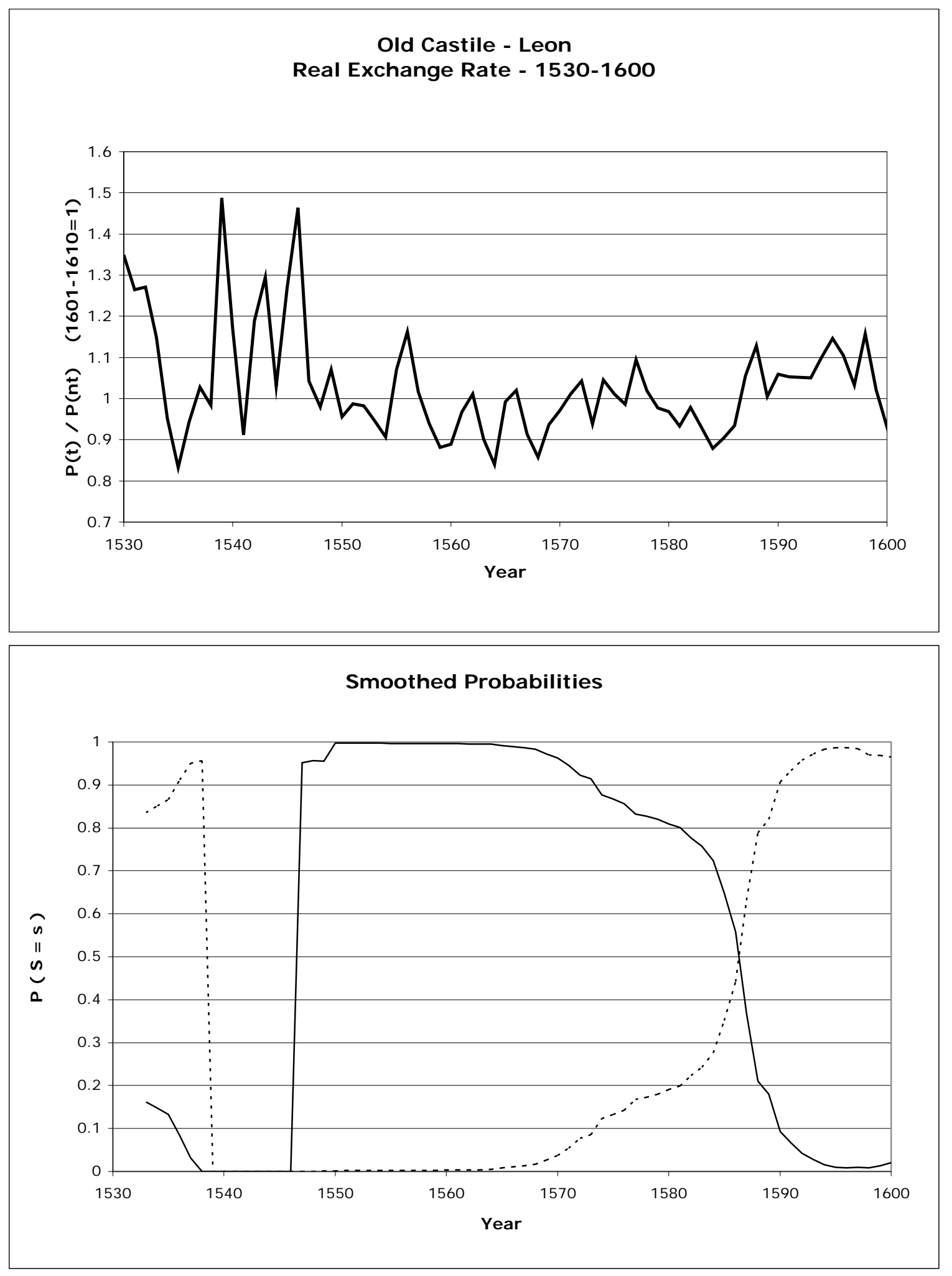

Probability of the series being in a "low" state (Dutch disease)

Probability of the series being in a "medium" state 
Figure 5
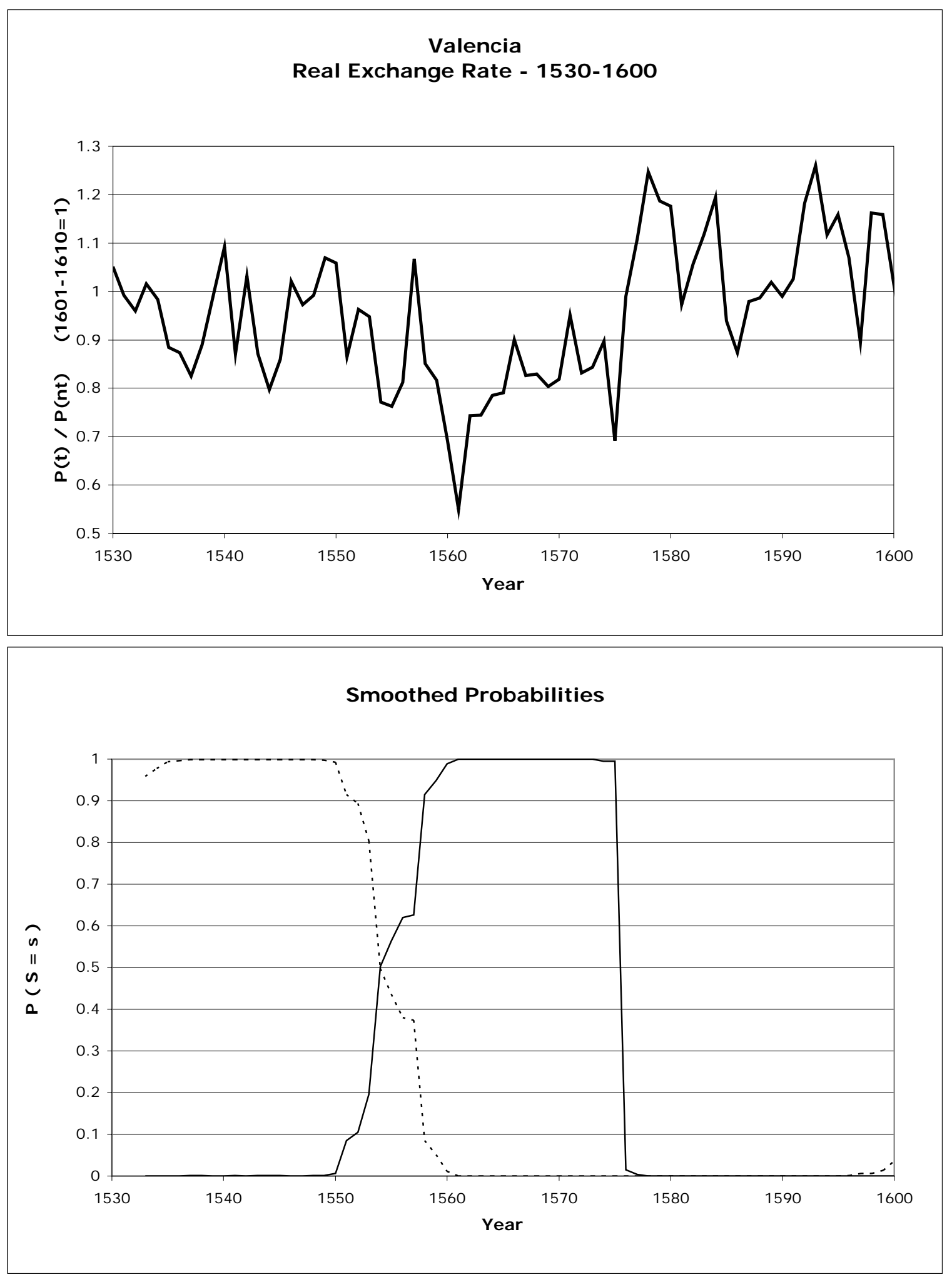

Probability of the series being in a "low" state (Dutch disease)

Probability of the series being in a "medium" state 